\title{
Ionic mechanisms limiting cardiac repolarization reserve in humans compared to dogs
}

Norbert Jost ${ }^{1,2}$, László Virág ${ }^{2}$, Philippe Comtois ${ }^{10,11}$, Balázs Ördög ${ }^{2,9}$, Viktória Szuts ${ }^{2}$, György Seprényi ${ }^{3}$, Miklós Bitay ${ }^{4}$, Zsófia Kohajda ${ }^{1}$, István Koncz ${ }^{2}$, Norbert Nagy ${ }^{1}$, Tamás Szél ${ }^{1}$, János Magyar ${ }^{7}$, Mária Kovács ${ }^{2}$, László G. Puskás ${ }^{6}$, Csaba Lengyel ${ }^{2,5}$, Erich Wettwer ${ }^{8}$, Ursula Ravens ${ }^{8}$, Péter P. Nánási ${ }^{7}$, Julius Gy. Papp ${ }^{1,2}$, András Varró ${ }^{1,2}$ and Stanley Nattel ${ }^{9,11}$

${ }^{1}$ Division of Cardiovascular Pharmacology, Hungarian Academy of Sciences, Szeged, Hungary

Departments of ${ }^{2}$ Pharmacology and Pharmacotherapy, ${ }^{3}$ Medical Biology, and ${ }^{4}$ Cardiac Surgery, Faculty of Medicine, University of Szeged, Szeged, Hungary

${ }^{5}$ First Department of Internal Medicine, Faculty of Medicine, University of Szeged, Szeged, Hungary

${ }^{6}$ Laboratory for Functional Genomics, Biological Research Center, Hungarian Academy of Sciences, Szeged, Hungary

${ }^{7}$ Department of Physiology, Faculty of Medicine, University of Debrecen, Hungary

${ }^{8}$ Department of Pharmacology and Toxicology, Dresden University of Technology, Germany

Department of ${ }^{9}$ Medicine and ${ }^{10}$ Physiology, Université de Montréal, Quebec, Canada

${ }^{11}$ Research Center, Montreal Heart Institute, Montreal, Quebec, Canada

\section{Key points}

- Cardiac repolarization, through which heart-cells return to their resting state after having fired, is a delicate process, susceptible to disruption by common drugs and clinical conditions.

- Animal models, particularly the dog, are often used to study repolarization properties and responses to drugs, with the assumption that such findings are relevant to humans. However, little is known about the applicability of findings in animals to man.

- Here, we studied the contribution of various ion-currents to cardiac repolarization in canine and human ventricle.

- Humans showed much greater repolarization-impairing effects of drugs blocking the rapid delayed-rectifier current $I_{\mathrm{Kr}}$ than dogs, because of lower repolarization-reserve contributions from two other important repolarizing currents (the inward-rectifier $I_{\mathrm{K} 1}$ and slow delayed-rectifier $I_{\mathrm{Ks}}$ ).

- Our findings clarify differences in cardiac repolarization-processes among species, highlighting the importance of caution when extrapolating results from animal models to man.

Abstract The species-specific determinants of repolarization are poorly understood. This study compared the contribution of various currents to cardiac repolarization in canine and human ventricle. Conventional microelectrode, whole-cell patch-clamp, molecular biological and mathematical modelling techniques were used. Selective $I_{\mathrm{Kr}}$ block $\left(50-100 \mathrm{nmol}^{-1}\right.$ dofetilide) lengthened $\mathrm{AP}$ duration at $90 \%$ of repolarization $\left(\mathrm{APD}_{90}\right)>3$-fold more in human than dog, suggesting smaller repolarization reserve in humans. Selective $I_{\mathrm{K} 1}$ block $\left(10 \mu \mathrm{mol}{ }^{-1} \mathrm{BaCl}_{2}\right)$ and $I_{\mathrm{Ks}}$ block ( $1 \mu \mathrm{moll}^{-1}$ HMR-1556) increased $\mathrm{APD}_{90}$ more in canine than human right ventricular papillary muscle. Ion current measurements in isolated cardiomyocytes showed that $I_{\mathrm{K} 1}$ and $I_{\mathrm{Ks}}$ densities were 3 - and 4.5-fold larger in dogs than humans, respectively. $I_{\mathrm{Kr}}$ density and kinetics were similar in human versus dog. $I_{\mathrm{Ca}}$ and $I_{\text {to }}$ were respectively $\sim 30 \%$ larger and $\sim 29 \%$ smaller in human, and $\mathrm{Na}^{+}-\mathrm{Ca}^{2+}$ exchange current was comparable. Cardiac mRNA levels for the main

N. Jost and L. Virág contributed equally to this work. Both are to be considered first authors. A. Varró and S. Nattel share senior authorship. 
$I_{\mathrm{K} 1}$ ion channel subunit Kir2.1 and the $I_{\mathrm{Ks}}$ accessory subunit minK were significantly lower, but mRNA expression of ERG and KvLQT1 ( $I_{\mathrm{Kr}}$ and $I_{\mathrm{Ks}} \alpha$-subunits) were not significantly different, in human versus dog. Immunostaining suggested lower Kir2.1 and $\operatorname{minK}$, and higher KvLQT1 protein expression in human versus canine cardiomyocytes. $I_{\mathrm{K} 1}$ and $I_{\mathrm{Ks}}$ inhibition increased the APD-prolonging effect of $I_{\mathrm{Kr}}$ block more in dog (by $56 \%$ and $49 \%$, respectively) than human (34 and 16\%), indicating that both currents contribute to increased repolarization reserve in the dog. A mathematical model incorporating observed human-canine ion current differences confirmed the role of $I_{\mathrm{K} 1}$ and $I_{\mathrm{Ks}}$ in repolarization reserve differences. Thus, humans show greater repolarization-delaying effects of $I_{\mathrm{Kr}}$ block than dogs, because of lower repolarization reserve contributions from $I_{\mathrm{K} 1}$ and $I_{\mathrm{Ks}}$, emphasizing species-specific determinants of repolarization and the limitations of animal models for human disease.

(Received 26 June 2013; accepted after revision 16 July 2013; first published online 22 July 2013)

Corresponding author A. Varró: Department of Pharmacology and Pharmacotherapy, Faculty of Medicine, University

of Szeged, H-6720 Szeged, Dóm tér 12, PO Box 427, Hungary. Email: varro.andras@med.u-szeged.hu

Abbreviations $\mathrm{AP}$, action potential; $\mathrm{APD}$, action potential duration; $I_{\mathrm{CaL}}$, L-type $\mathrm{Ca}^{2+}$ current; $I_{\mathrm{K} 1}$, inward rectifier $\mathrm{K}^{+}$ current; $I_{\mathrm{Kr}}$, rapid delayed-rectifier $\mathrm{K}^{+}$current; $I_{\mathrm{Ks}}$, slow delayed-rectifier $\mathrm{K}^{+}$current; $I_{\mathrm{to}}$, transient-outward current; $\mathrm{N}_{\mathrm{CX}}, \mathrm{Na}^{+}-\mathrm{Ca}^{2+}$ exchanger current.

\section{Introduction}

Many drugs can affect transmembrane $\mathrm{K}^{+}$currents and thereby cause therapeutically useful (Honhloser \& Woosley, 1994; Brendorp et al. 2001) or harmful (Surawicz, 1989; El-Sherif, 1992) effects. Blocking cardiac $\mathrm{K}^{+}$channels prolongs repolarization and refractoriness, producing Class III antiarrhythmic effects both in ventricles and atria (Sing \& Vaughan-Williams, 1970). Excessive lengthening of repolarization may induce life-threatening ventricular tachyarrhythmias like torsades de pointes (Hondeghem \& Snyders, 1990; El-Sherif, 1992). Predicting the risk of such serious side effects is a major challenge in cardiac safety pharmacology. Torsade-risk estimation is hampered by a lack of easily usable methods and by incomplete understanding of the repolarization process in both experimental animals and humans.

Repolarization is controlled by two major inward currents $\left(\mathrm{Na}^{+}\right.$and $\mathrm{Ca}^{2+}$ ) and four major outward $\mathrm{K}^{+}$currents (rapid and slow delayed-rectifier $\left(I_{\mathrm{Kr}}\right.$ and $\left.I_{\mathrm{Ks}}\right)$, transient-outward $\left(I_{\mathrm{to}}\right)$ and inward-rectifier $\left(I_{\mathrm{K} 1}\right)$ currents), as well as other less well-characterized currents, electrogenic pumps and exchangers (Nerbonne \& Kass, 2005). According to the concept of 'repolarization reserve' (Roden, 1998), normal repolarization is accomplished by multiple different potassium channels providing a strong safety reserve for repolarization. Thus, in normal cardiac tissue the pharmacological block or impairment of a single type of potassium channel does not necessarily lead to marked QT interval prolongation. However, in situations where the density of one or more types of potassium channels is decreased by congenital disorders or remodelling, inhibition of other potassium channels may lead to unexpectedly augmented action potential duration (APD) prolongation resulting in proarrhythmic reactions. In genetic channelopathies certain potassium channels, which normally contribute to repolarization, can attenuate the capability of the heart to repolarize (Biliczki et al. 2002; Jost et al. 2005).

Transmembrane ion currents flow through channel complexes composed of $\alpha$ - and $\beta$-subunit proteins including ERG (encoded by $K C N H 2)$, $\operatorname{minK}$ (KCNE1), MiRP1-4 (KCNE25), KvLQT1 (KCNQ1), Kv4.3 (KCND3), Kv1.4 (KCNA4), KChIP2 (KCNIP2) and Kir2.1-2.4 (KCNJ2, KCNJ12, KCNJ4, KCNJ14). These proteins are abundantly expressed in mammalian hearts, but their relative contributions vary considerably among species (Varró et al. 2000; Zicha et al. 2003). Differential $\mathrm{K}^{+}$ current expression causes interspecies differences in the response to $\mathrm{K}^{+}$channel blocking drugs, affecting predictive value for their effects in humans (Nerbonne \& Kass, 2005). Despite the very common use of the dog in evaluating long-QT risk in man, there is little quantitative information available about the relative responses of human versus canine hearts to QT-prolonging interventions or regarding underlying differences in ionic currents. Here, we compared the contribution of three particularly important $\mathrm{K}^{+}$currents, $I_{\mathrm{Kr}}, I_{\mathrm{K} 1}$ and $I_{\mathrm{Ks}}$, to repolarization in dog and human hearts, studied the molecular basis of differences observed, and analysed their importance with a mathematical model.

\section{Methods}

For methodological details, please see Supplemental Methods.

\section{Ethical approval and species}

Patients. Hearts were obtained from organ donors whose non-diseased hearts were explanted to obtain 
pulmonary and aortic valves for transplant surgery. Before cardiac explantation, organ donors did not receive medication apart from dobutamine, furosemide, and plasma expanders. The investigations conformed to the principles of the Declaration of Helsinki. Experimental protocols were approved by the University of Szeged and National Scientific and Research Ethical Review Boards (Nos. 51-57/1997OEj and 4991-0/2010-1018EKU (339/PI/010)). After explantation, each heart was perfused with cardioplegic solution (for contents see Online Data Supplement) and kept cold $\left(4-6^{\circ} \mathrm{C}\right)$ for $2-4 \mathrm{~h}$ prior to dissection.

Animals. All experiments complied with the Guide for the Care and Use of Laboratory Animals (NIH publication No 85-23, revised 1985). The protocols were approved by the Review Board of the Department of Animal Health and Food Control of the Ministry of Agriculture and Rural Development, Hungary (XII./01031/000/2008 and XIII./1211/2012). Adult mongrel dogs of either sex weighing $8-16 \mathrm{~kg}$ were anaesthetized with pentobarbital $\left(30 \mathrm{mg} \mathrm{kg}^{-1}\right.$ I.V.). Hearts were removed through right lateral thoracotomies and rinsed in modified Locke's solution containing $\left(\mathrm{mmoll}^{-1}\right)$ : $\mathrm{Na}^{+} 140, \mathrm{~K}^{+} 4, \mathrm{Ca}^{2+}$ 1.0, $\mathrm{Mg}^{2+} 1.0, \mathrm{Cl}^{-} 126, \mathrm{HCO}_{3}{ }^{-} 25$ and glucose $11 ; \mathrm{pH}$ $7.35-7.45,95 \% \mathrm{O}_{2}-5 \% \mathrm{CO}_{2}, 37^{\circ} \mathrm{C}$.

\section{Action potential measurements}

Action potentials (APs) were recorded in right ventricular trabeculae and papillary muscle preparations $(<2 \mathrm{~mm}$ diameter), from 15 non-diseased human donor hearts ( 9 male and 6 female, age $=44.6 \pm 5.9$ years) and 25 dogs, with conventional microelectrode techniques, as described in detail previously (Varró et al. 2000; Biliczki et al. 2002; Jost et al. 2005).

\section{Transmembrane current measurements}

Cell isolation. Ventricular cardiomyocytes were enzymatically dissociated from the left ventricular midmyocardial free wall of 10 additional non-diseased human donor hearts ( 5 male and 5 female, age $=43.4 \pm 5.3$ years) and 21 dog hearts with previously described procedures (Varró et al. 2000; Biliczki et al. 2002; Jost et al. 2005).

Experimental protocol. Rod-shaped, striated cardiomyocytes were placed in a recording chamber on the stage of inverted microscopes Olimpus, IX51 (Olympus Ltd, Tokyo, Japan) and Nikon TMS (Nikon Ltd, Tokyo, Japan) and allowed to adhere. The solutions, equipment and voltage-clamp protocols (see Supplemental Methods) were as previously detailed for $\mathrm{K}^{+}$currents (Varró et al. 2000; Biliczki et al. 2002; Jost et al. 2005) and for L-type $\mathrm{Ca}^{2+}$ current $\left(I_{\mathrm{CaL}}\right)$ and $\mathrm{Na}^{+}-\mathrm{Ca}^{2+}$ exchanger (NCX) current (Hobai et al. 1997; Birinyi et al. 2005).

\section{Molecular biology}

Reverse transcription (RT) quantitative polymerase chain reaction (qPCR). Left ventricular midmyocardial free-wall samples were obtained from eight human ( 7 male and 5 female, age $=45.2 \pm 3.7$ years) and eight dog hearts, and snap-frozen in liquid $\mathrm{N}_{2}$. RNA was isolated with the Qiagen RNase Tissue kit (Amersham). Reverse transcription (RT) was performed with Superscript-II RNase H-Reverse Transcriptase (Invitrogen). QPCR was performed on a RotorGene-3000 instrument (Corbett Research, Australia) with gene-specific primers (Supplemental Table 1) and SybrGreen. Expression values were normalized to $\beta$-actin. Triplicate standard curves were run for each experiment. Data analysis was performed with the Pfaffl method (Pfaffl, 2001), correcting for amplification efficiency differences.

Western blot. Membrane proteins were obtained from the same samples used for qPCR. Samples were suspended in lysis buffer, dounced and centrifuged $(2000 \times g, 10 \mathrm{~min}$, $4^{\circ} \mathrm{C}$ ). The supernatant was resuspended in lysis buffer containing $2 \%$ Triton X-100. After $1.5 \mathrm{~h}$ incubation on ice, samples were ultracentrifuged $(100000 \times g$, $35 \mathrm{~min}, 4^{\circ} \mathrm{C}$ ), supernatants collected and stored at $-70^{\circ} \mathrm{C}$. Protein concentration was measured by the Lowry method and samples diluted in loading buffer for SDS-polyacrylamide gel electrophoresis. Fractionated proteins were transferred onto polyvinylidine difluoride (PVDF) membranes, blocked in Tris buffer supplemented with Tween-20 (TBST) and 10\% non-fat milk (BioRad, USA), then incubated overnight $\left(4^{\circ} \mathrm{C}\right)$ with rabbit polyclonal primary antibodies against Kir2.1, Kir2.2, Kir2.3, ERG, minK and KvLQT1, goat anti-Kir2.4 (Santa Cruz Biotechnology) or mouse monoclonal anti- $\alpha$-sarcomeric actin (DAKO). Bound primary antibodies were detected with anti-rabbit, anti-goat or anti-mouse secondary antibodies conjugated to horseradish peroxidase. Immunoreactivity was visualized with enhanced chemoluminescence and analysed with Image ${ }^{\mathrm{TM}}$. All values were quantified relative to internal controls on the same samples ( $\alpha$-actin for Kir2.x, KvLQT1 and $\operatorname{minK}$, GAPDH for ERG).

Immunohistochemistry. Isolated $\operatorname{dog}(n=6)$ and human ( 3 male, 1 female, age $=48.3 \pm 4.7$ years) left ventricular midmyocardial free-wall ventricular cardiomyocytes on glass coverslips were fixed with acetone. Samples were rehydrated with calcium-free phosphate-buffered saline (PBS) and blocked for $2 \mathrm{~h}$ with PBST (PBS with $0.01 \%$ Tween) containing $1 \% \mathrm{BSA}$ at room temperature. Incubation with the primary polyclonal rabbit antibody for $1.5 \mathrm{~h}$ at room temperature was followed by $1 \mathrm{~h}$ incubation with secondary antibodies (Alexafluor 
448-conjugated goat anti-rabbit IgG). Control samples were incubated only with secondary antibody.

Fluorescence images were obtained with an Olympus FV1000 confocal laser-scanning microscope and standardized parameter settings. Images were quantified in greyscale TIFF format with ImageQuant ${ }^{\mathrm{TM}}$ software. On each image, three to five random strips were selected and fluorescence profiles plotted. Baseline pixels were identified and subtracted from total profile area.

Statistics. Results are expressed as means \pm SEM. Statistical significance was determined by two-tailed Student's $t$ tests and ANOVA with Bonferroni-corrected post hoc $t$ tests as appropriate. Results were considered significant for $P<0.05$.

\section{Results}

\section{Current densities}

$I_{\mathrm{K} 1}$ was recorded with $300 \mathrm{~ms} 0.33 \mathrm{~Hz}$ test pulses from a holding potential of $-80 \mathrm{mV}$ (Fig. $1 \mathrm{~A}$ ) and quantified based on end-pulse amplitude. $I_{\mathrm{K} 1}$ was significantly larger in dog than human cardiomyocytes (Fig. $1 B$ ). Maximum outward current density at $-60 \mathrm{mV}$ was almost 3-fold greater in dog versus human $\left(1.72 \pm 0.07 \mathrm{pA} \mathrm{pF}^{-1}\right.$ vs. $0.65 \pm 0.1 \mathrm{pA} \mathrm{pF}^{-1}, n=21-28$, Fig. $1 C$ ).

\section{A}
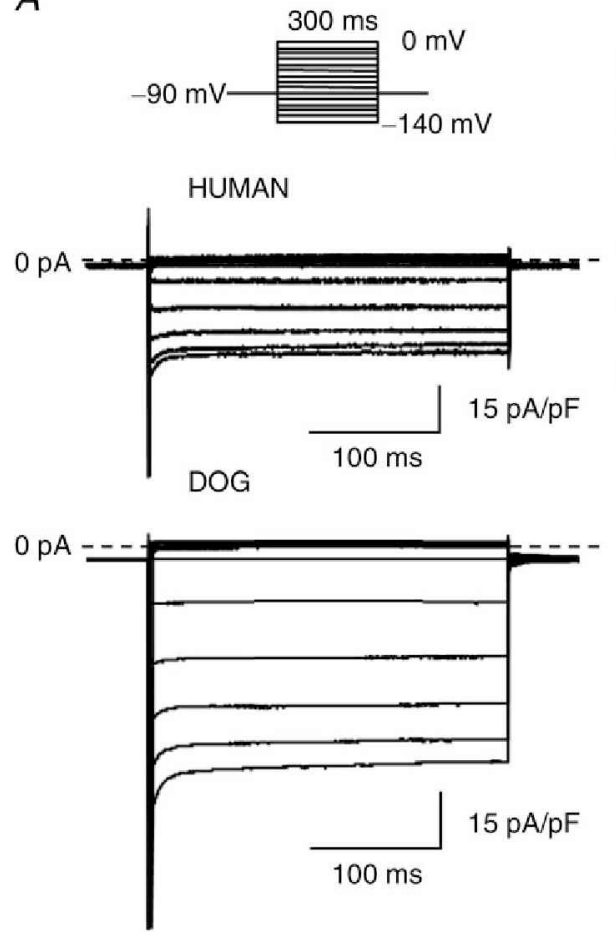

Mean $I_{\mathrm{Kr}}$ and $I_{\mathrm{Ks}}$ data are shown in Fig. 2. $I_{\mathrm{Kr}}$ data are shown in panels $A-C$ and $I_{\mathrm{Ks}}$ data in panels $D-F$. Examples of original $I_{\mathrm{Kr}}$ recordings are in the top row, and $I_{\mathrm{Ks}}$ recordings in the middle row. $I_{\mathrm{Kr}}$ tail current at $-40 \mathrm{mV}$ after $1000 \mathrm{~ms}$ test pulses $(0.05 \mathrm{~Hz})$ did not differ significantly between species (Fig. $2 \mathrm{C}$ ). In contrast, $I_{\mathrm{Ks}}$ tail current at $-40 \mathrm{mV}$ after $5000 \mathrm{~ms}$ test pulses $(0.1 \mathrm{~Hz})$ was about 4.5 -fold larger in dog versus human (Fig. $2 F$ ).

To estimate the magnitude of $I_{\mathrm{K} 1}, I_{\mathrm{Kr}}$ and $I_{\mathrm{Ks}}$ activated during the cardiac action potential, we compared the amplitudes of the $\mathrm{BaCl}_{2}$-sensitive $\left(I_{\mathrm{K} 1}\right), \mathrm{E}$-4031-sensitive $\left(I_{\mathrm{Kr}}\right)$ and L-735,821-sensitive $\left(I_{\mathrm{Ks}}\right)$ currents during 'action potential' test pulses. These test pulses were obtained by digitizing representative right ventricular human and canine action potentials recorded with conventional microelectrodes (Fig. 3A). Under these conditions, the $\mathrm{BaCl}_{2}$-sensitive $I_{\mathrm{K} 1}$ difference current flowing during the AP was substantially larger in dog than in human (Fig. $3 B$ ), while the E-4031-sensitive $I_{\mathrm{Kr}}$ difference current was similar (Fig. 3C). The L-735,821-sensitive $I_{\mathrm{Ks}}$ during the action potential plateau phase was very small and not clearly different between the two species (Fig. 3D).

The activation and deactivation kinetics of $I_{\mathrm{Kr}}$ and $I_{\mathrm{Ks}}$ measured at the whole range of activating and deactivating membrane potentials are shown in Fig. 4 . The $I_{\mathrm{Ks}}$ kinetics of human and dog are quite similar (Fig. $4 A$ and $B$ ). $I_{\mathrm{Kr}}$

Figure 1. Inward-rectifier potassium current $\left(I_{\mathrm{K} 1}\right)$ in human and dog ventricular cardiomyocytes $A$, original $/ K_{1}$ recordings in a human (top traces) and a dog (bottom traces) ventricular myocyte. Voltage protocol shown above traces. $B$, mean $\pm \mathrm{SEM} / \mathrm{k} 1$ density-voltage relations. C, mean $\pm \mathrm{SEM} / \mathrm{k} 1$ density at $-60 \mathrm{mV}$ (left) and $-140 \mathrm{mV}$ (right) membrane potentials. ${ }^{*} P<0.05,{ }^{* *} P<0.01$ dog versus human. $n=$ number of experiments. 
deactivation (Fig. $4 \mathrm{C}$ ) at voltages $(-70$ and $-60 \mathrm{mV}$ ) relevant to physiological current deactivation (i.e. near the resting potential) consisted predominantly of a rapid phase with a time constant of 200-400 ms, not significantly different between human and dog. At more positive voltages, the kinetics became more clearly biexponential. The rapid-phase time constants were similar at all voltages for human and dog. At voltages negative to $-30 \mathrm{mV}$, the slow-phase time constant was also similar, whereas at more positive voltages the slow-phase time constant was greater in dog.
Species-dependent contributions of $I_{\mathrm{K} 1}, I_{\mathrm{Kr}}$ and $I_{\mathrm{Ks}}$ to repolarization

The contribution of $I_{\mathrm{K} 1}, I_{\mathrm{Kr}}$ and $I_{\mathrm{Ks}}$ to repolarization was investigated (Fig. 5) by selectively blocking these currents with $\mathrm{BaCl}_{2}\left(10 \mu \mathrm{moll}^{-1}\right)$, dofetilide $\left(50 \mathrm{nmoll}^{-1}\right)$ and HMR-1556 $\left(1 \mu \mathrm{moll}^{-1}\right)$, respectively. We previously reported that $10 \mu \mathrm{mol}^{-1} \mathrm{BaCl}_{2}$ blocks over $70 \%$ of $I_{\mathrm{K} 1}$ without affecting $I_{\mathrm{Kr}}, I_{\mathrm{Ks}}$ and $I_{\mathrm{to}}$ (Biliczki et al. 2002). In human ventricular muscle, selective inhibition of $I_{\mathrm{K} 1}$ only marginally prolonged AP duration (APD, by $4.8 \pm 1.5 \%$ ),


Figure 2. $I_{\mathrm{Kr}}$ and $I_{\mathrm{Ks}}$ in human and dog ventricular cardiomyocytes

$A$ and $B$, original $/ I_{\mathrm{Kr}}$ recordings from a human $(A)$ and a dog $(B)$ ventricular cardiomyocyte. $C$, mean $\pm S E M / K r$ tail current density-voltage relations. $D$ and $E$, original $/ K_{s}$ recordings from a human $(A)$ and a $\operatorname{dog}(B)$ ventricular cardiomyocyte. $F$, mean \pm SEM $/$ Ks tail current density-voltage relations. $n=$ number of experiments. ${ }^{*} P<0.05$, ${ }^{* *} P<0.01$ and ${ }^{* * *} P<0.001$. 
while it caused significant APD prolongation in dog (17.9 $\pm 2.1 \%, P<0.05$ vs. human, $n=7-11$ ). In contrast, selective inhibition of $I_{\mathrm{Kr}}$ caused markedly greater APD prolongation in humans $(56.3 \pm 8.4 \%)$ compared to the $\operatorname{dog}(21.7 \pm 2.5 \%, P<0.05, n=17-20)$. The differential response was due to differences in maximal effects and not drug sensitivity per se, as shown by similar dofetilide $\mathrm{IC}_{50}$ values between species (Supplemental Fig. 1). $I_{\mathrm{Ks}}$ block did not significantly alter APD in either studied species.

\section{Contributions to repolarization reserve}

We then studied the role of $I_{\mathrm{K} 1}$ and $I_{\mathrm{Ks}}$ differences in contributing to the larger APD increases produced by $I_{\mathrm{Kr}}$ block in human versus canine cardiomyocytes. Tissues were exposed to dofetilide in the absence or presence of $10 \mu \mathrm{moll}^{-1} \mathrm{BaCl}_{2}$ to inhibit $I_{\mathrm{K} 1}$ (Fig. $6 \mathrm{~A}$ ) or HMR-1566 to block $I_{\mathrm{Ks}}$ (Fig. 6B). The change in APD (relative to $\mathrm{BaCl}_{2}$-free control) caused by dofetilide alone indicates the effect of the drug with repolarization reserve intact, whereas the change caused in the presence of $\mathrm{BaCl}_{2}$ (dofetilide $+\mathrm{BaCl}_{2}$ vs. $\mathrm{BaCl}_{2}$ alone) indicates the effect with $I_{\mathrm{K} 1}$ suppressed, i.e. the contribution of $I_{\mathrm{K} 1}$ to repolarization reserve. In human cells, dofetilide increased $\mathrm{APD}$ by $59 \pm 5 \%$ in the presence of $\mathrm{BaCl}_{2}$, versus $44 \pm 4 \%$ in the absence of $\mathrm{BaCl}_{2}$. The relative increase from $44 \%$ prolongation with $I_{\mathrm{K} 1}$ intact to $59 \%$ prolongation with $I_{\mathrm{K} 1}$ removed indicates a $34 \%$ increase in $I_{\mathrm{Kr}}$ blocking effect with $I_{\mathrm{K} 1}$ suppressed. For dog cells, dofetilide increased

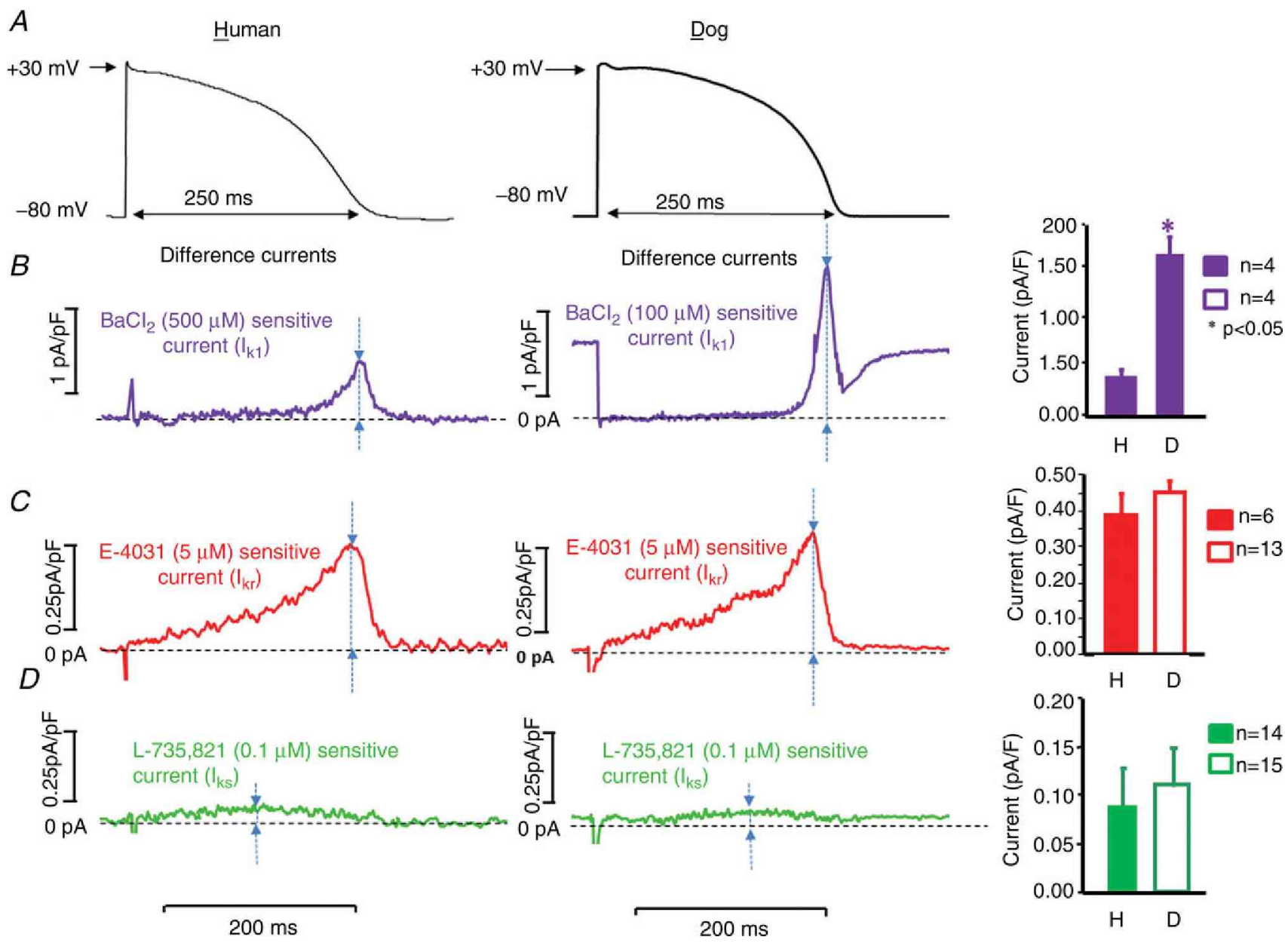

Figure 3.

A, currents recorded with action potential voltage-clamp waveforms, obtained by recording typical normal human or canine ventricular action potentials with a conventional microelectrode in a multicellular papillary muscle preparation. B-D, original $\mathrm{BaCl}_{2}\left(/ \mathrm{K} 1\right.$, purple recordings, B), E-4031 (/ $/ \mathrm{Kr}_{\mathrm{r}}$, red recordings, C) and L-735,821 ( $/ \mathrm{Ks}_{\mathrm{s}}$, green recordings, $D$ ) sensitive currents obtained by digitally subtracting currents elicited by action potential test pulses in the presence of the blocker from current in the same cell prior to the blocker in human (left panels) and dog (middle panels) ventricular myocytes. Right panels represent corresponding mean amplitudes of drug-sensitive $I_{\mathrm{K} 1}, I_{\mathrm{Kr}}$ and $I_{\mathrm{Ks}}$ currents in 4-13 cells per measurement. Arrows indicate the points at which current amplitudes were determined. Bars represent means \pm SEM; corresponding $n$ values are provided for each current and species. 
APD by $25 \pm 2 \%$ in the presence of $\mathrm{BaCl}_{2}$, versus $16 \pm 2 \%$ in the absence of $\mathrm{BaCl}_{2}$, indicating a $56 \%$ increase in $I_{\mathrm{Kr}}$ blocking effect with $I_{\mathrm{K} 1}$ suppression. This result confirms a larger contribution of $I_{\mathrm{K} 1}$ to repolarization reserve in the dog versus man. For $I_{\mathrm{Ks}}$ (Fig. $6 \mathrm{~B}$ ), dofetilide increased APD by $63 \pm 4 \%$ in the absence of HMR-1566-induced $I_{\mathrm{Ks}}$ block in humans, versus $73 \pm 2 \%$ in the presence of HMR-1566, an increase of $16 \%$ attributable to the loss of the $I_{\mathrm{Ks}}$ contribution. In the dog, dofetilide prolonged APD by $29 \pm 5 \%$ in the absence of HMR-1566, versus $43 \pm 4 \%$ in its presence, indicating a $49 \%$ enhancement attributable to loss of $I_{\mathrm{Ks}}$. Thus, the larger $I_{\mathrm{Ks}}$ of canine tissues also contributes to greater repolarization reserve versus humans.

\section{Ion channel subunit expression}

To assess the potential molecular basis for the observed differences in $I_{\mathrm{K} 1}$ and $I_{\mathrm{Ks}}$ densities, qPCR was applied for subunits underlying $I_{\mathrm{K} 1}, I_{\mathrm{Kr}}$ and $I_{\mathrm{Ks}}$. Gene expression values for $I_{\mathrm{K} 1}$-encoding subunits are shown in Fig. $7 \mathrm{~A}$. Kir2.1-encoding mRNA (KCNJ2) was $>2$-fold more abundant in the dog than the total mRNA level for Kir2.1,
$A$

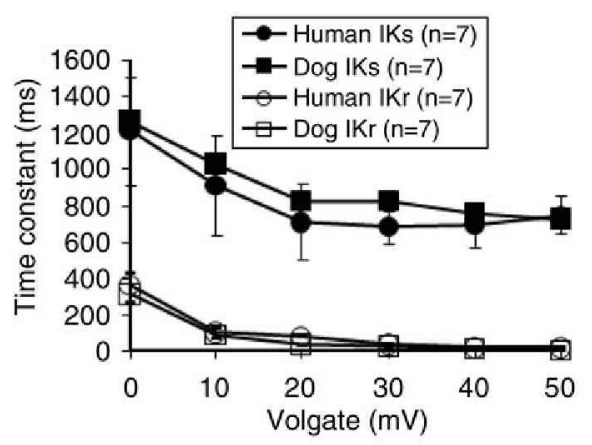

$B$

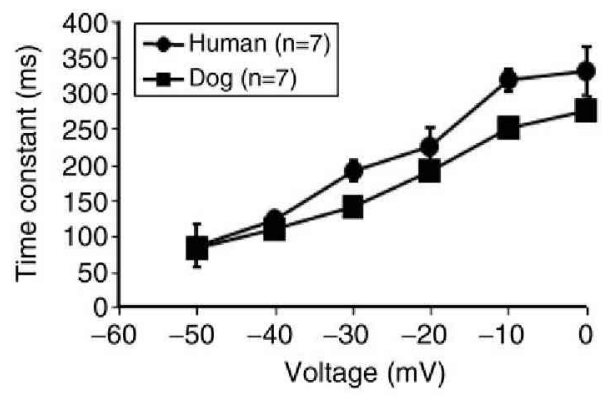

C

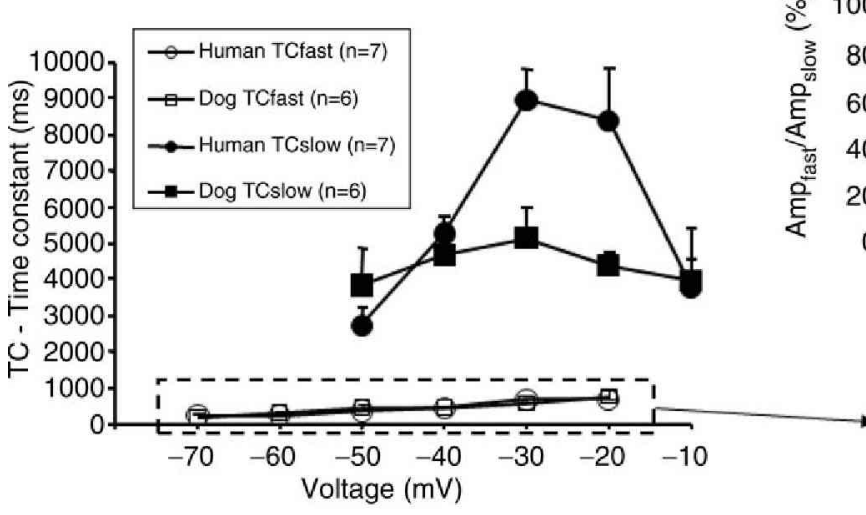

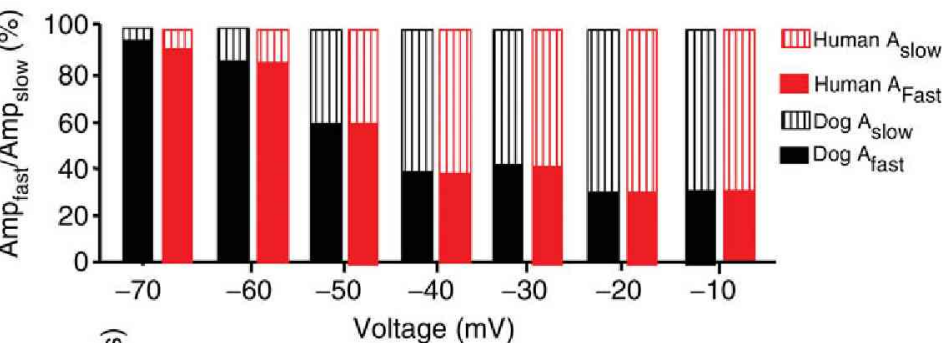

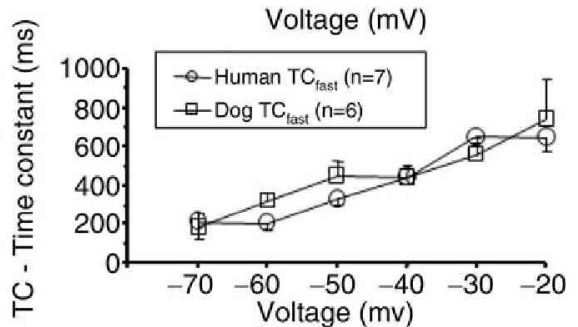

Figure 4. The voltage dependence of the activation and deactivation kinetics of human and canine $I_{\mathrm{Kr}}$ and $I_{\mathrm{Ks}}$

A, voltage dependence of activation kinetics. $I_{\mathrm{Kr}}$ and $I_{\mathrm{Ks}}$ were activated by test pulses with durations from 10 to $5000 \mathrm{~ms}$, to test potentials ranging from 0 to $50 \mathrm{mV}$; then the cells were clamped back to $-40 \mathrm{mV}$. The amplitudes of tail currents as a function of the duration of the depolarization were well fitted by single exponentials. $B$, the voltage dependence of $/ \mathrm{Ks}$ deactivation kinetics was determined by activating / $\mathrm{ks}$ with $5000 \mathrm{~ms}$ test pulses to $50 \mathrm{mV}$ from a holding potential of $-40 \mathrm{mV}$. Then the cells were clamped back for $2 \mathrm{~s}$ to potentials ranging from -50 to $0 \mathrm{mV}$ (pulse frequency $0.1 \mathrm{~Hz}$ ) and the deactivation time course of the tail current was fitted by a single exponential function. $C$, the voltage dependence of $/ \mathrm{Kr}$ deactivation kinetics was determined by activating $/ \mathrm{Kr}$ with $1000 \mathrm{~ms}$ test pulses to $30 \mathrm{mV}$ from a holding potential of $-40 \mathrm{mV}$. Then the cells were clamped for $16 \mathrm{~s}$ to potentials ranging from -70 to $0 \mathrm{mV}$ (pulse frequency $0.05 \mathrm{~Hz}$ ) and the deactivation time course of the tail current was fitted by a double exponential function. The left panel shows the voltage dependence of slow and fast time constants. An expanded version of the results for voltage dependence of the fast time constants is provided in the right bottom panel. The right top panel shows the relative amplitudes of the fast and slow components at different voltages in dog (black) and human (red) ventricular myocytes. 
Kir2.2, Kir2.3 and Kir2.4 combined in the human. The $K C N H 2$ gene encoding $I_{\mathrm{Kr}}$ was equivalently expressed in canine and human ventricle (Fig. $7 B$ ). KCNQ1 gene expression was not significantly different between human and dog (Fig. $7 C$ ), but the KCNE1 gene encoding the $I_{\mathrm{Ks}} \beta$-subunit protein minK was $\sim 6$-fold more strongly expressed in dog. Examples of Western blots for Kir2.x, ERG, KvLQT1 and minK proteins are shown in Fig. $7 D-F$. Mean data are provided in Table 1. In agreement with qPCR-findings, Kir2.1 was significantly stronger in canine than human hearts, whereas Kir2.2 was stronger in humans. ERG was detected as two larger molecular mass bands (Fig. $7 E)$ corresponding to ERG1a $(\sim 150$ and $165 \mathrm{kDa}$ ) and two smaller bands corresponding to ERG1b ( $~ 85$ and $95 \mathrm{kDa}$ ). ERG1a was less abundant in human samples, while ERG1b band intensities were not significantly different from dogs. The very similar expression of ERG1b, in agreement with physiological data (Figs $2 C$ and 3 ), is consistent with recent evidence for a particularly important role of ERG1b in forming functional $I_{\mathrm{Kr}}$ (Sale et al. 2008) and with a recent study of Purkinje fibre remodelling with heart failure (Maguy et al. 2009). MinK bands were also stronger in dog hearts, whereas KvLQT1 band intensity was greater in human.

We also performed immunohistochemical analyses on isolated cardiomyocytes (Fig. 8), with identical image settings for human versus canine cells. Examples are shown in Fig. 8A. Anti-Kir2.1 showed significantly stronger staining for canine cells (Fig. $8 B$ ), and Kir2.3 staining was also slightly but significantly greater for dog. In contrast, ERG staining was comparable for the two species (Fig. 8C). KvLQT1 staining was modestly but significantly greater for human cells (Fig. $8 D$ ), but in keeping with the qPCR data, mink staining was much greater $(\sim 5$-fold) for dog cells versus human. Supplemental Fig. 2 presents negative controls for immunostaining measurements.
$A$

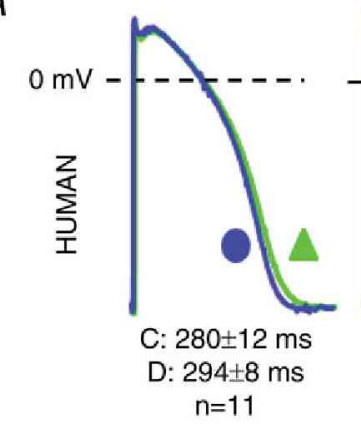

C: $280 \pm 12 \mathrm{~ms}$

$n=11$
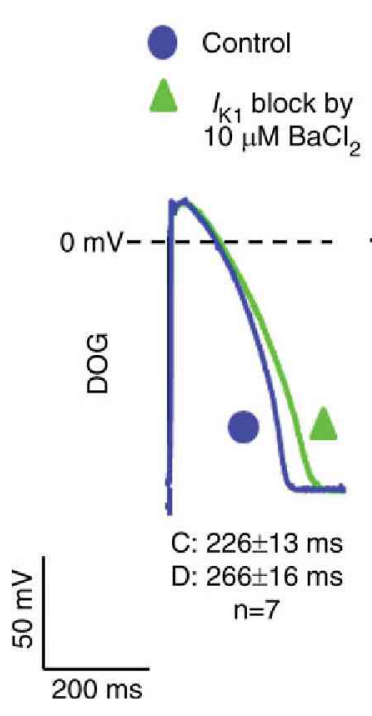

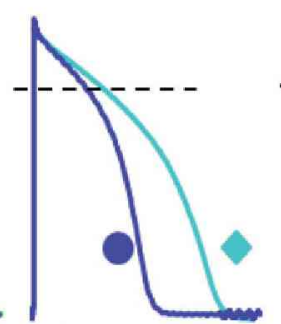

C: $278 \pm 19 \mathrm{~ms}$

D: $433 \pm 29 \mathrm{~ms}$

$n=17$
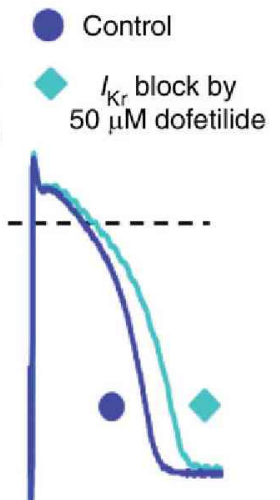

C: $241 \pm 15 \mathrm{~ms}$

D: $291 \pm 16 \mathrm{~ms}$ $\mathrm{n}=20$

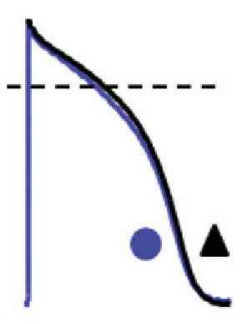

C: $285 \pm 12 \mathrm{~ms}$

D: $293 \pm 6 \mathrm{~ms}$ $n=12$
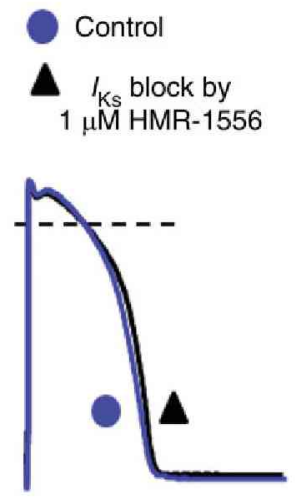

C: $221 \pm 11 \mathrm{~ms}$

D: $236 \pm 6 \mathrm{~ms}$ $n=14$

Cycle length $=1000 \mathrm{~ms}$

B

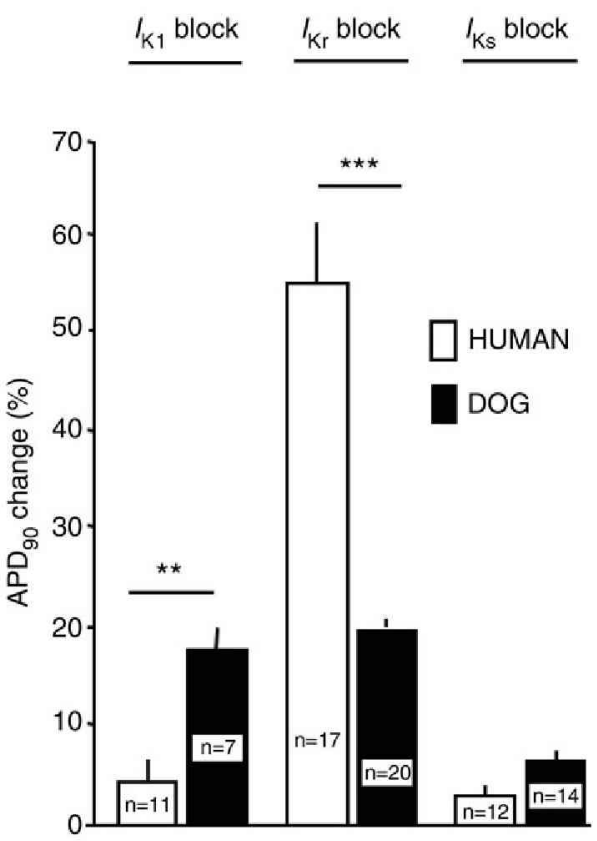

Figure 5. Effect of selective $I_{\mathrm{K} 1}(10 \mu \mathrm{M} \mathrm{BaCl}), I_{\mathrm{Kr}}\left(50 \mathrm{nmol} \mathrm{I}{ }^{-1}\right.$ dofetilide $)$ or $I_{\mathrm{Ks}}\left(1 \mu \mathrm{mol} \mathrm{I}^{-1} \mathrm{HMR}-1566\right)$ block on APs measured with standard microelectrode techniques in canine and human right papillary muscles

A, recordings (at $1 \mathrm{~Hz}$ ) before and after 40 min superfusion with $\mathrm{BaCl}_{2}$ (left), dofetilide (middle) or $\mathrm{HMR}-1566$ (right). Corresponding mean \pm SEM values for controls (C) and drug (D) effects are given under each action potential recordings. $B$, mean \pm SEM AP duration at $90 \%$ of repolarization (APD90) under each condition. $n=$ number of experiments, ${ }^{* *} P<0.01$ and ${ }^{* * *} P<0.001$. 


\section{Other ionic current differences and in silico assessment}

The functional, pharmacological, and biochemical data described above all point to reduced repolarization reserve due to smaller $I_{\mathrm{Ks}}$ and $I_{\mathrm{K} 1}$ expression in human hearts as the basis for their larger APD prolonging response to $I_{\mathrm{Kr}}$ inhibition. To assess the potential role of other ionic current differences, we compared several other currents between canine and human hearts. $I_{\text {to }}$, recorded as the difference between peak and end-pulse current during $300 \mathrm{~ms}$ depolarizing pulses from $-90 \mathrm{mV}(0.33 \mathrm{~Hz})$, was smaller in human versus dog (Fig. 9A). $I_{\mathrm{CaL}}$ evoked by 400 ms test pulses from $-40 \mathrm{mV}$ was $\sim 30 \%$ larger in human (Fig. 9B). Recovery kinetics of $I_{\text {to }}$ (Supplemental Fig. $3 A$ ) and $I_{\mathrm{Ca}}$ (Supplemental Fig. $3 B$ ) currents were not statistically different in myocytes from human and dog ventricle. $\mathrm{Ni}^{2+}\left(10 \mathrm{mmol}^{-1}\right)$-sensitive NCX current was not significantly different between species (Fig. 9C and $D$ ).

To assess the contribution of ionic current components to repolarization reserve in human versus canine hearts, we initially adapted the Hund-Rudy dynamic (HRd) canine ventricular AP model (Hund \& Rudy, 2004). We then adjusted the current densities in the dog model according to the experimentally observed differences in humans, to obtain 'humanized' APs (see Supplemental Methods). Supplemental Fig. 4 shows the resulting simulations: $\mathrm{APD}_{90}$ at $1 \mathrm{~Hz}$ in the dog model was $209 \mathrm{~ms}$, versus human $264 \mathrm{~ms}$, close to experimentally determined values (APD 90 at $1 \mathrm{~Hz}$ : dog $227 \mathrm{~ms}$, human $270 \mathrm{~ms}) . I_{\mathrm{Kr}}$ block increased $\mathrm{APD}_{90}$ by $26 \%$ in the human AP model (Supplemental Fig. $4 A$ ) versus $15.5 \%$ in the dog model (Supplemental Fig. $4 B$ ),
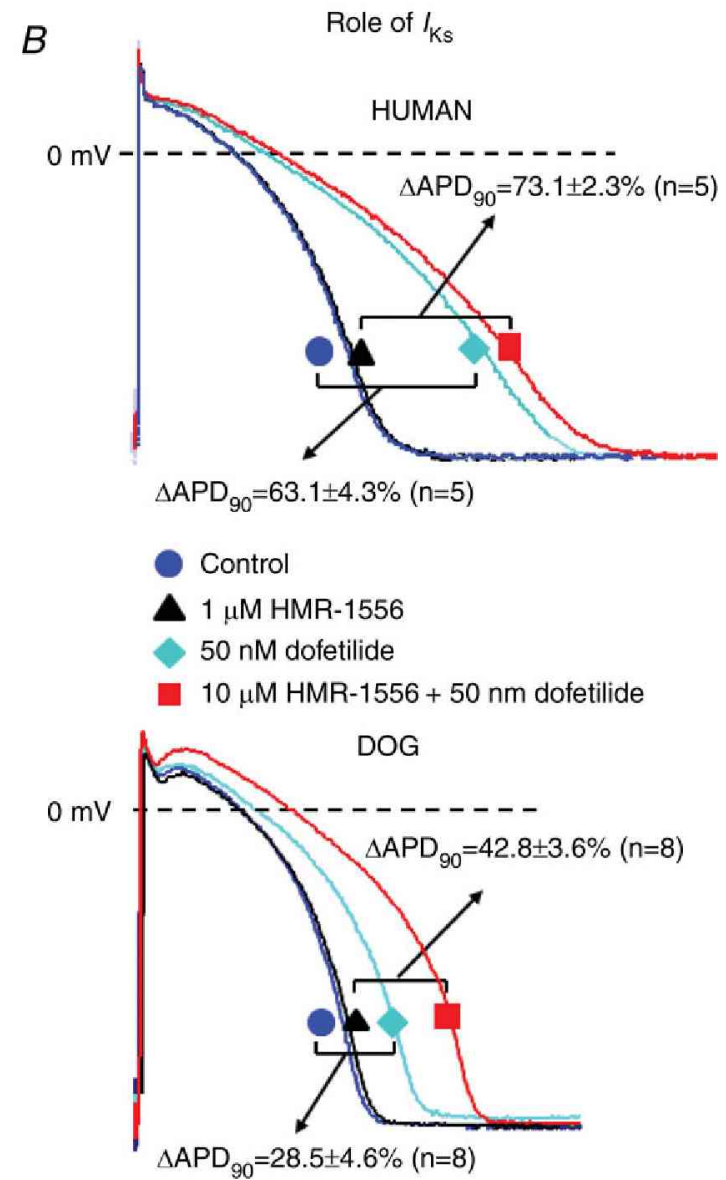

Figure 6. Effect of combined $I_{\mathrm{Kr}}+I_{\mathrm{K} 1}$ and $I_{\mathrm{Kr}}+I_{\mathrm{Ks}}$ inhibition in human and dog ventricular muscle preparations (endocardial impalements)

$A$, representative APs at baseline (circle), following exposure to $10 \mu \mathrm{mol} \mathrm{I}^{-1} \mathrm{BaCl}_{2}$ (triangle), $50 \mathrm{nmol}^{-1}$ dofetilide (diamond), and combined $10 \mu \mathrm{moll}^{-1} \mathrm{BaCl}_{2}+50 \mathrm{nmoll}^{-1}$ dofetilide (rectangle) in human (top traces) and dog (bottom traces) ventricular muscle. Brackets show average differences between conditions indicated. $B$, representative APs at baseline (circle), following exposure to $1 \mu \mathrm{mol} \mathrm{I}^{-1} \mathrm{HMR}-1566$ (triangle), $50 \mathrm{nmol} \mathrm{I}^{-1}$ dofetilide (diamond), and combined $1 \mu \mathrm{mol} \mathrm{I}^{-1} \mathrm{HMR}-1566+50 \mathrm{nmol} \mathrm{I}^{-1}$ dofetilide (rectangle) in human (top traces) and dog (bottom traces) ventricular muscle. Brackets show average differences between conditions indicated. 
qualitatively consistent with experimental findings (56\%, $22 \%$ respectively). $I_{\mathrm{Kr}}$ inhibition increased human $\mathrm{APD}_{90}$ by $71.2 \%$ in the presence of $I_{\mathrm{K} 1}$ block, indicating a $173.8 \%$ increase in $I_{\mathrm{Kr}}$ blocking effect with the $I_{\mathrm{K} 1}$ contribution to repolarization reserve suppressed (Supplemental Fig. 4A). For the canine model (Supplemental Fig. $4 B$ ), $I_{\mathrm{Kr}}$ block increased $\mathrm{APD}_{90}$ by $45.4 \%$ in the presence of $I_{\mathrm{K} 1}$ block, indicating a $193.5 \%$ increase in $I_{\mathrm{Kr}}$ blocking effect when $I_{\mathrm{K} 1}$ is decreased. This result is consistent with experimental data suggesting a larger contribution of $I_{\mathrm{K} 1}$ to repolarization reserve in the dog. $I_{\mathrm{Kr}}$ block prolonged human $\mathrm{APD}_{90}$ by $29.4 \%$ (Supplemental Fig. 4 C) in the presence of $I_{\mathrm{Ks}}$ inhibition, an increase of $14.6 \%$ attributable to the loss of $I_{\mathrm{Ks}}$ contribution to repolarization reserve. For the dog AP model (Supplemental Fig. 4D), $I_{\mathrm{Kr}}$ block prolonged APD by $23.8 \%$ in the presence of $I_{\mathrm{Ks}}$ inhibition, indicating a $53.6 \%$ enhancement attributable to loss of the repolarization reserve effect of $I_{\mathrm{Ks}}$. Thus, the model also confirms the importance of larger $I_{\mathrm{Ks}}$ to greater repolarization reserve in dogs. Finally, we used the model to explore the contributions of $I_{\mathrm{CaL}}$ and $I_{\text {to }}$ differences. Supplemental Fig. 5 shows the APD changes induced by $I_{\mathrm{Kr}}$ inhibition in canine (panel $A$ ) and human (panel B) models. The effect of $I_{\mathrm{Kr}}$ inhibition in the human model was then verified with $I_{\mathrm{CaL}}$ (panel $C$ ) or $I_{\text {to }}$ (panel $D$ ) modified to canine values. APD 90 increases in the human model resulting from $I_{\mathrm{Kr}}$ inhibition were minimally affected by substituting canine $I_{\text {to }}$ in the human model. Substituting canine $I_{\mathrm{CaL}}$ into the human model enhanced the $I_{\mathrm{Kr}}$ blocking effect on APD, whereas if canine $I_{\mathrm{CaL}}$ contributed to the larger repolarization reserve in the dog it should reduce the APD prolonging effect. These results indicate that $I_{\mathrm{CaI}}$ and $I_{\mathrm{to}}$ differences do not contribute to the enhanced repolarization reserve in the dog.

To assess further the contribution of ionic current components to repolarization reserve in human versus canine hearts, we performed the analysis in a reverse
A

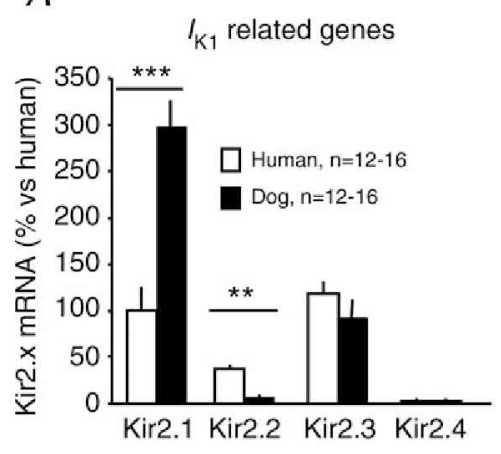

$B$

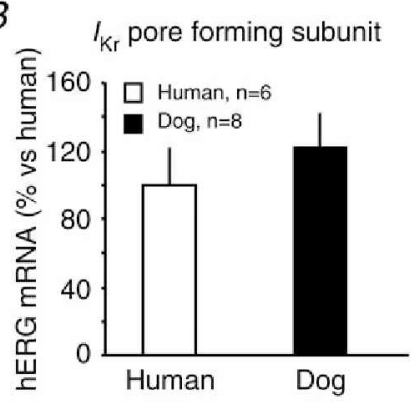

C

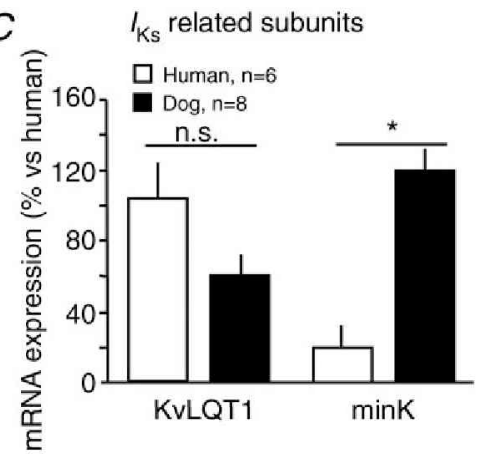

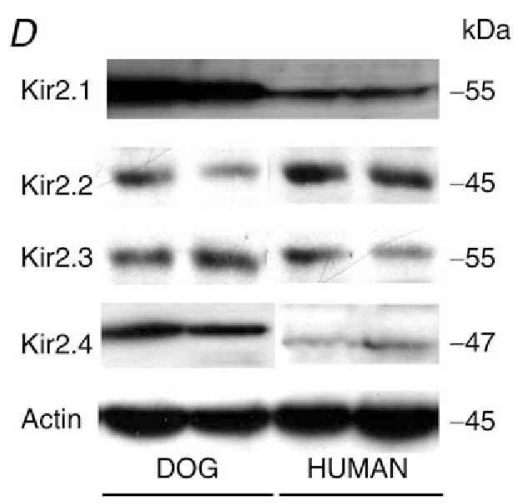

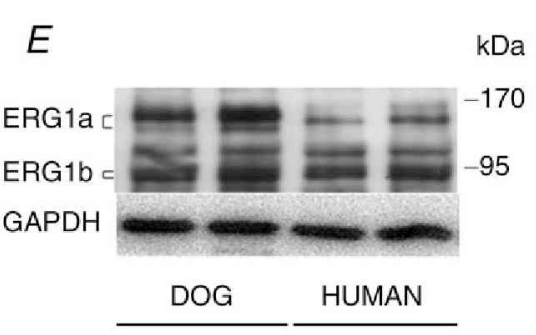

F

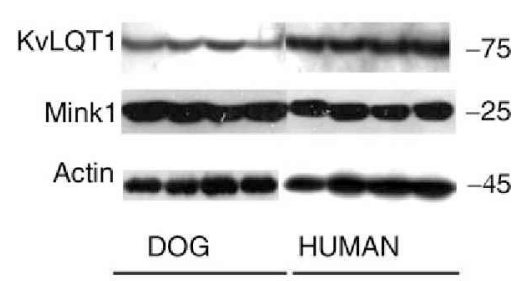

Figure 7. Expression of $I_{\mathrm{K} 1}$-related (Kir2.x), $I_{\mathrm{Kr}}$ pore-forming (ERG) and $I_{\mathrm{Ks}}$-related subunits (KvLQT1 and $\operatorname{minK}$ )

A-C, mean \pm SEM mRNA levels of Kir2.x (A), ERG $(B)$ and KVLQT1/minK (C) subunits in left ventricular human $(n=6-8)$ and $\operatorname{dog}(n=816)$ preparations. ${ }^{*} P<0.05,{ }^{* *} P<0.01$ and

${ }^{* * *} P<0.001 . n=$ number of experiments. $D-F$, representative Western blots for Kir2.x (D), ERG $(E)$ and KVLQT1/minK $(F)$ in human and dog left ventricular preparations. 
Table 1. Protein expression data for ion channel subunits in human versus dog ventricular tissues

\begin{tabular}{llll}
\hline Currents/subunits & \multicolumn{1}{c}{ Subunit $\dagger$} & Human $\dagger$ & Dog \\
\hline$I_{\text {K1 } 1 \text { subunits }}$ & Kir2.1 $(n=4 / 4)$ & $0.22 \pm 0.01$ & $0.45 \pm 0.06^{*}$ \\
& Kir2.2 $(n=4 / 4)$ & $0.64 \pm 0.03^{* *}$ & $0.37 \pm 0.02$ \\
& Kir2.3 $(n=4 / 4)$ & $0.10 \pm 0.01$ & $0.09 \pm 0.007(P=\mathrm{NS})$ \\
& Kir2.4 $(n=4 / 4)$ & $0.01 \pm 0.002$ & $0.20 \pm 0.009^{* *}$ \\
$I_{\text {Kr }}$ subunits & ERG1a $(n=5 / 4)$ & $0.30 \pm 0.16$ & $0.97 \pm 0.27^{* *}$ \\
& ERG1b $(n=5 / 4)$ & $0.71 \pm 0.05$ & $0.73 \pm 0.07(P=\mathrm{NS})$ \\
$I_{\text {Ks }}$ subunits & KvLQT1 $(n=4 / 4)$ & $0.15 \pm 0.01^{* *}$ & $0.05 \pm 0.003$ \\
& MinK $(n=4 / 4)$ & $0.31 \pm 0.01$ & $0.40 \pm 0.05^{*}$ \\
\hline
\end{tabular}

Mean \pm SEM data. ${ }^{*} P<0.05,{ }^{* *} P<0.01,{ }^{* * *} P<0.001 . n$ designates number of samples from humans $/$ dogs. $\dagger$ All values are expressed as arbitrary optical density units, quantified relative to an internal control on the same sample ( $\alpha$-actin for Kir2.x, KvLQT1 and minK, GAPDH for ERG).

fashion, with the more recently published O'Hara-Rudy dynamic (ORd) human ventricular AP model (O'Hara et al. 2011, see Supplemental Methods). Figure 10 shows the resulting simulations: $\mathrm{APD}_{90}$ at $1 \mathrm{~Hz}$ in the canine and human models were $210 \mathrm{~ms}$ and $271 \mathrm{~ms}$ (versus experimental $\mathrm{APD}_{90}$ at $1 \mathrm{~Hz}$ : dog $227 \mathrm{~ms}$, human $270 \mathrm{~ms}$ ). $I_{\mathrm{Kr}}$ block increased $\mathrm{APD}_{90}$ by $42.4 \%$ in the human versus $29.4 \%$ in the dog model, consistent with experimental findings (56\%, 22\% respectively). With the human ionic model (Fig. $10 \mathrm{~A}$ ), $I_{\mathrm{Kr}}$ block increased APD by $58.7 \%$ in the presence of $I_{\mathrm{K} 1}$ block, versus $42.4 \%$ in the absence of $I_{\mathrm{K} 1}$ block. These results indicate a $38.3 \%$ increase in $I_{\mathrm{Kr}}$ blocking effect on APD with $I_{\mathrm{K} 1}$ blocked. For the dog ionic model (Fig. 10B), $I_{\mathrm{Kr}}$ block increased APD by $45.8 \%$ in the presence of $I_{\mathrm{K} 1}$ block, versus $29.4 \%$ in the absence of $I_{\mathrm{K} 1}$ block, indicating a $55.7 \%$ increase in $I_{\mathrm{Kr}}$ blocking effect when $I_{\mathrm{K} 1}$ was decreased. This result confirms the notion based on our experimental data, indicating a larger contribution of $I_{\mathrm{K} 1}$ to repolarization reserve in the dog compared to man. $I_{\mathrm{Kr}}$ block increased APD by $42.4 \%$ in the absence of $I_{\mathrm{Ks}}$ block in the human model (Fig. 10C), versus $50.3 \%$ in the presence of $I_{\mathrm{Ks}}$ block, an increase of $18.5 \%$ attributable to the loss of $I_{\mathrm{Ks}}$ contribution to repolarization reserve. In the dog ionic model (Fig. 10D), $I_{\mathrm{Kr}}$ block prolonged APD by $29.4 \%$ in the absence of $I_{\mathrm{Ks}}$ block, versus $46.9 \%$ in its presence, indicating a $59.4 \%$ enhancement attributable to loss of the repolarization reserve effect of $I_{\mathrm{Ks}}$. Thus, the model also confirms the importance of larger $I_{\mathrm{Ks}}$ to greater repolarization reserve in dogs. Finally, we also used this modelling approach to explore the contributions of $I_{\mathrm{CaL}}$ and $I_{\text {to }}$ differences, and found no evidence that they contribute to the differences in $I_{\mathrm{Kr}}$ blocking effects between human and dog (Supplemental Fig. 6).

\section{Discussion}

In this study, we found that $I_{\mathrm{Kr}}$ inhibition causes substantially greater APD prolongation in human versus canine ventricular muscle, indicating reduced repolarization reserve in man. Ionic current measurements showed larger $I_{\mathrm{K} 1}$ and $I_{\mathrm{Ks}}$ densities in canine versus human hearts and APD studies with selective blockers indicated larger repolarization reserve in canine hearts due to stronger $I_{\mathrm{K} 1}$ and $I_{\mathrm{Ks}}$ contributions. Expression studies suggested that the ionic current differences are due to species-related differences in mRNA expression of underlying subunits.

\section{Experimental model considerations}

We compared experimental data between non-diseased human donor hearts and canine hearts. There is a potential difference in relative maturity/age between the humans and dogs that provided our tissue samples, which were essentially impossible to control, other than by virtue of the fact that both study populations comprised adult and not senescent individuals. Important transmural and regional differences in ion channel subunit protein expression and current densities exist within the heart. Extrapolation of our findings to the whole heart must therefore be cautious. We were careful to perform all measurements in corresponding regions of canine and human hearts to ensure comparability. Current and $\mathrm{mRNA} /$ protein densities were measured from the left ventricular midmyocardial free-wall, but APs were recorded from right ventricular subendocardial tissue. This was done both for technical reasons (standard microelectrode recordings from left ventricular tissue were difficult to obtain and more likely to be contaminated by subendocardial Purkinje fibres) and to maximize data from each human heart by using all available tissues. We had to optimize the information obtained from each human heart, because functional measurements were greatly limited by the unpredictable and infrequent availability of human donor tissue and because of the short time window for meaningful functional measurement after tissue procurement. Of note, our patch-clamp/biochemical 
results in left ventricular free-wall were fully compatible with our AP data from right ventricular tissues, indicating that at least for these two widely separated regions the observations are consistent.

\section{Relationship to previous studies of repolarizing currents and repolarization reserve}

Our data suggest important expression differences in Kir2.x channel mRNA expression between human and
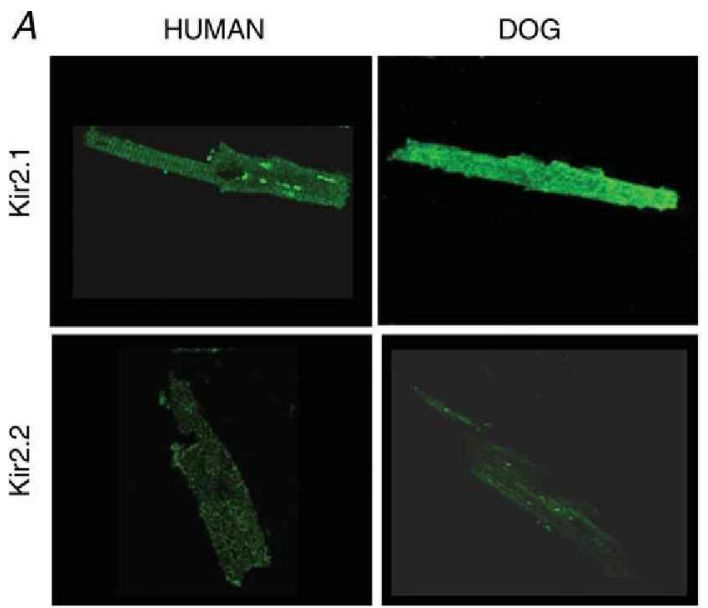

$B$
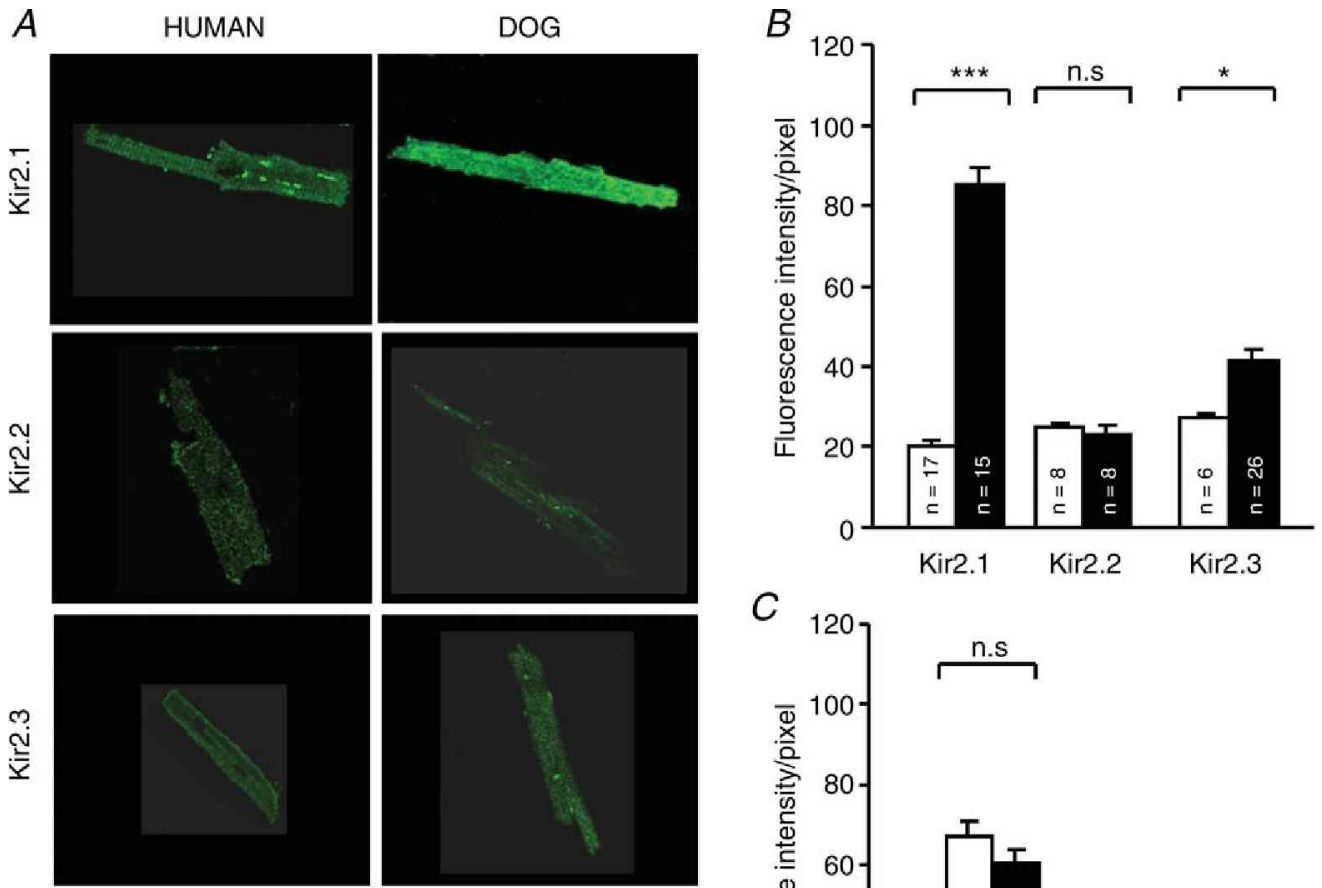

C
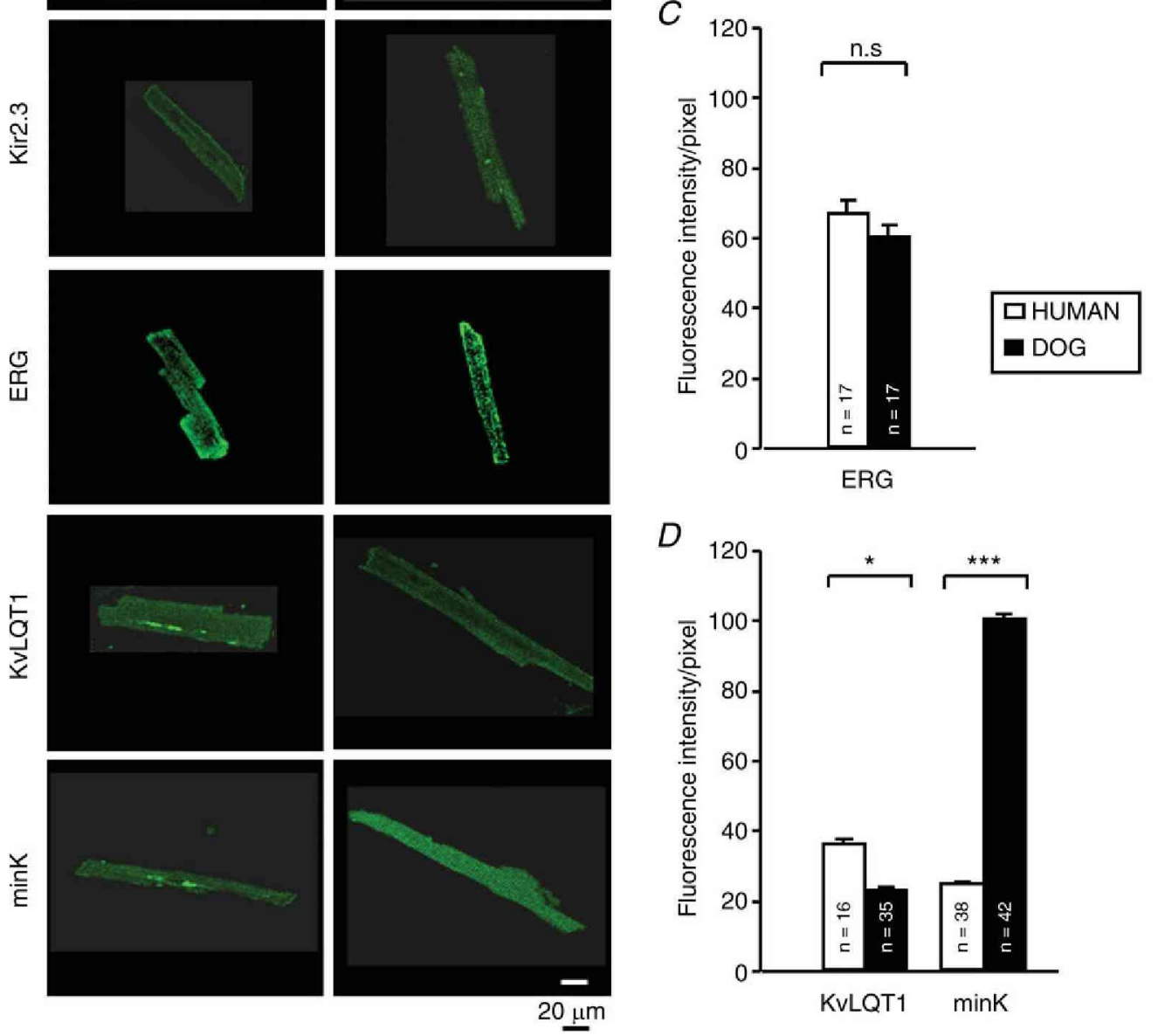


pore-forming (ERG) and $/ \mathrm{Ks}_{\mathrm{s}}$-related (KvLQT1 and MinK) subunits in left ventricular cardiomyocytes $A$, representative immunofluorescence images of human (left) and dog (right) cardiomyocytes. Dark-field images of typical human and dog ventricular cardiomyocytes are shown at the bottom. $B-D$, mean $\pm S E M$ fluorescence intensities for various subunits in human versus dog cardiomyocytes. Results are shown for Kir2.x (B), ERG (C) and KVLQT1 and minK $(D)$ subunits. $n=$ number of experiments. ${ }^{*} P<0.05$ and ${ }^{* * *} P<0.001$ for dog versus human.Constant image-settings were maintained for each construct for all cells studied. 
dog ventricle. Kir2.1 expression was about 3-fold greater in the dog than human, but Kir2.2 and Kir2.4 levels were negligible in dogs. In human hearts, we found Kir2.3 mRNA expression comparable with that of Kir2.1, generally considered the principal subunit underlying $I_{\mathrm{K} 1}$ (Dhamoon \& Jalife, 2005). Significant Kir2.3 protein expression in human ventricle was also detected by Western blot (Fig. 7D). Kir2.1 currents display strong inward rectification, whereas Kir2.3 inward rectification is incomplete and negative slope conductance is less steep (Dhamoon et al. 2004). In our study, the current-voltage relation of $I_{\mathrm{K} 1}$ in dog strongly resembles that previously reported for Kir 2.1 channels, but in human cells resembles better a mixture of Kir2.1 and Kir2.3 properties (Dhamoon et al. 2004) corresponding to mRNA data.

\section{A}

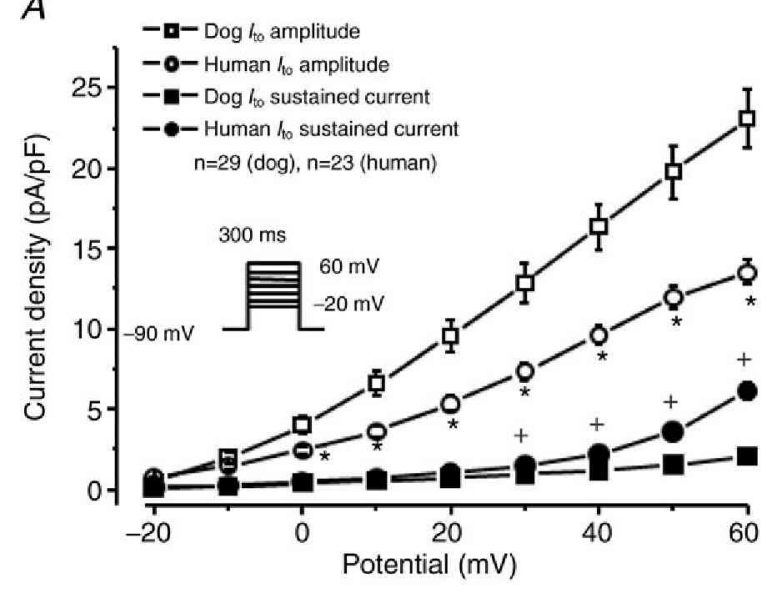

C

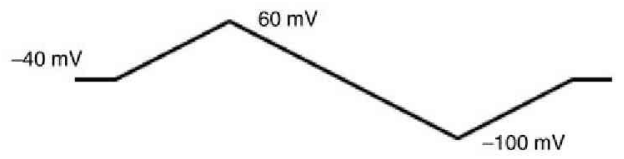

$\mathrm{Ni}^{2+}$-sensitive current (difference current)
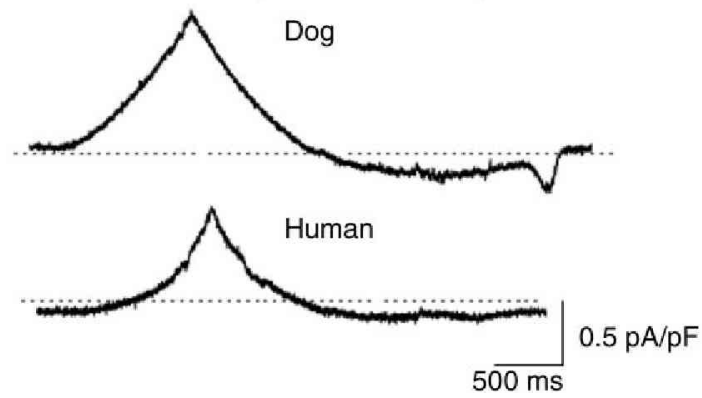

Protein quantification showed lesser ERGla abundance in human compared to dog tissue while expression of ERG1b was not different. A higher ERG1b:ERG1a expression ratio in humans suggests the possibility of different channel subunit stoichiometry in human tissue versus dog. This difference might have two functional consequences. First, partially due to the accelerated activation kinetics of heteromeric channels compared to homomeric channels consisting of ERG1a only, the relative contribution of $I_{\mathrm{Kr}}$ to the repolarization reserve is expected to be higher in humans (Sale et al. 2008; Larsen \& Olesen, 2010). Secondly, ERG1a-ERG1b subunit stoichiometry could also affect drug binding affinity of dofetilide to $I_{\mathrm{Kr}}$ channels, as slightly higher $\mathrm{IC}_{50}$ values were obtained for ERG1a-1b heteromeric channels

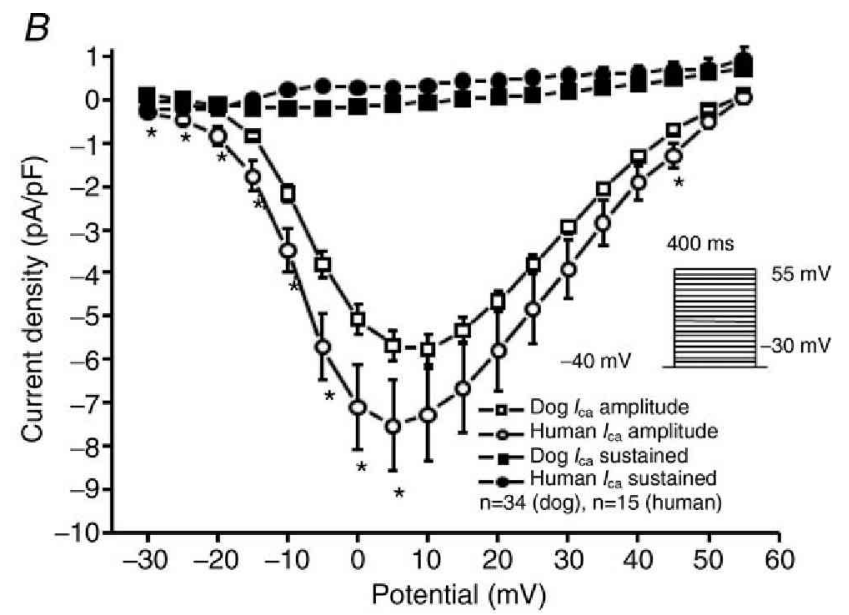

$D$ Normalized NCX at $-80 \mathrm{mV}$ and $+50 \mathrm{mV}$

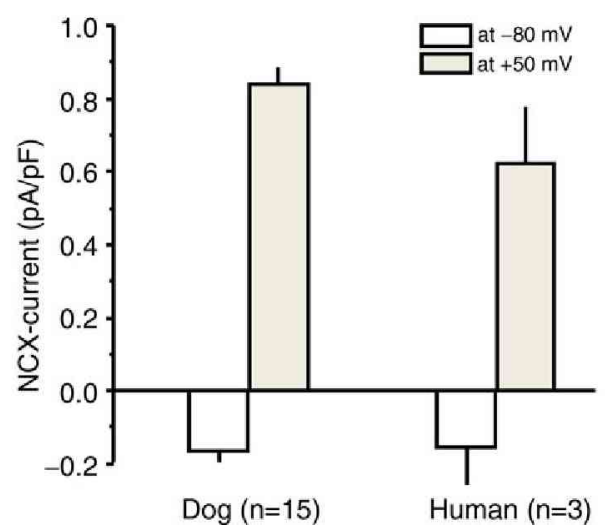

Figure 9.

$A$, Ito current-voltage density ( $1-V$ relationship) relation obtained with the inset protocol. ${ }^{*} P<0.05$ and $+P<0.05$ for human versus dog. $I-V$ relationships for $I_{\text {to }}$ are determined and depicted as peak current (open circles and squares) and as sustained current (closed circles and squares) as well. $B$, ICaL current-voltage density relation obtained with the insetprotocol. ${ }^{*} P<0.05$ for human $v$ s. dog. $I-V$ relationships for $/ C a$ are determined and depicted as peak current (open circles and squares) and as sustained current (closed circles and squares) as well. $C$. ramp protocol was applied to measure current before and after application of $\mathrm{Ni}^{2+}\left(10 \mathrm{mmol}^{-1}\right)$ under conditions to isolate NCX. Representative $\mathrm{Ni}^{2+}$-sensitive difference currents from dog and human cells are shown below. $\mathrm{D}$, mean inward (at $-80 \mathrm{mV}$ ) and outward (at $+50 \mathrm{mV}$ ) NCX current density values. 
as compared to ERG1a homomer channels (150 nM vs. $100 \mathrm{nM}$, respectively; Abi-Gerges et al. 2011). We have not detected any significant difference in the kinetic behaviour of $I_{\mathrm{Kr}}$ in humans versus dogs and dofetilide affinity was not different based on concentration-response curves (Supplemental Fig. 1). Thus, relative expression on Western blots may not reflect accurately relative local subunit expression in ion channels.

Relatively little information is available about the molecular basis of differential repolarization patterns among species. APD prolongation and early afterdepolarization formation upon exposure to $I_{\mathrm{Kr}}$ blocking drugs varies widely, with rabbits being the most sensitive, guinea-pigs, swine and sheep the least, and dogs intermediate (H. R. Lu et al. 2001). Guinea-pigs have particularly large, and rabbits particularly small, $I_{\mathrm{Ks}}(\mathrm{Z}$. Lu et al. 2001). This difference results from weaker mink expression in the rabbit, despite stronger KvLQT1 expression in rabbits (Zicha et al. 2003). Interestingly, this expression difference resembles what we observed for human versus dog in the present study, with dogs having much larger minK, but smaller KvLQT1, expression than humans, along with considerably larger $I_{\mathrm{Ks}}$ density. Dumaine \& Cordeiro (2007) also observed larger $I_{\mathrm{K} 1}$ and $I_{\mathrm{Ks}}$, along with similar $I_{\mathrm{Kr}}$, for dog compared to rabbit. MinK, on the other hand, has also been found to modulate hERG and Kv4.3 current densities and gating of the channels (Pourrier et al. 2003). Therefore, other currents in addition to $I_{\mathrm{Ks}}$, such as $I_{\mathrm{Kr}}$ and $I_{\text {to }}$ might be potentially influenced by the relatively lower minK expression level in human ventricles we found in this study.

\section{Possible implications}

Larger APD prolongation in human tissues versus dog in response to $I_{\mathrm{Kr}}$ blockade, despite similar $I_{\mathrm{Kr}}$, is a novel finding that may have important implications. Based on the present results, despite observations that
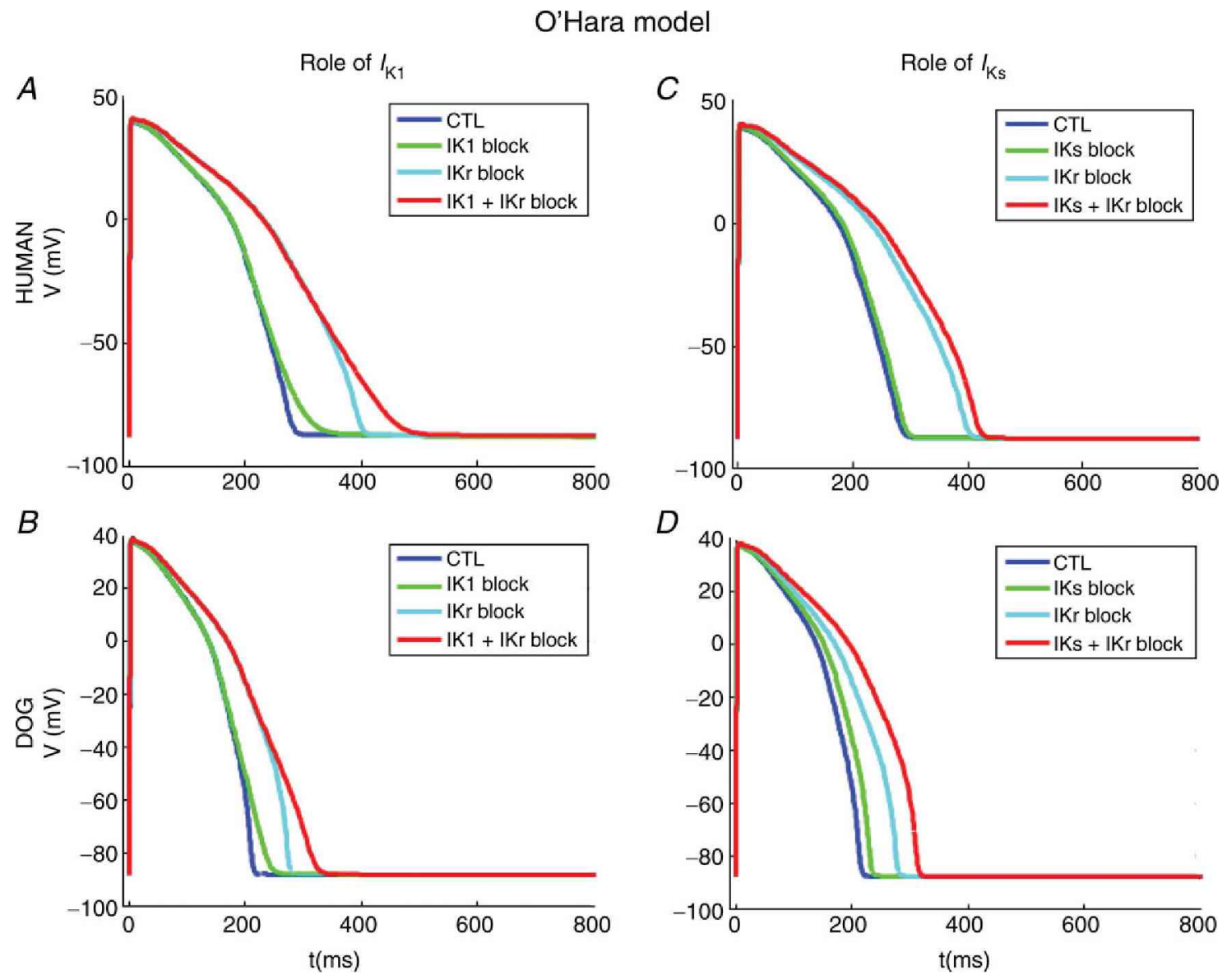

Figure 10. Simulations of effect of combined $I_{\mathrm{K}}+I_{\mathrm{K} 1}$ and $I_{\mathrm{Kr}}+I_{\mathrm{Ks}}$ inhibition on human and dog ventricular muscle APs by applying the O'Hara dynamic (ORd) canine ventricular AP model

$A$, simulated human APs at control, following $/ K_{k}$ block ( $70 \%$ reduction), $/ k_{r}$ block ( $50 \%$ reduction), and combined $I_{\mathrm{K} 1}+I_{\mathrm{Kr}}$ block. $B$, corresponding data for $\operatorname{dog} I_{\mathrm{K} 1}+I_{\mathrm{Kr}}$ block. $C$, simulated human APs at control, following $I_{\mathrm{Ks}}$ block $\left(50 \%\right.$ reduction), $I_{\mathrm{Kr}}$ block $\left(50 \%\right.$ reduction), and combined $I_{\mathrm{Ks}}+I_{\mathrm{Kr}}$ block. $D$, corresponding data for dog $\mathrm{K}_{\mathrm{Ks}}+\mathrm{K}_{\mathrm{Kr}}$ block. 
the properties of individual $\mathrm{K}^{+}$channels in dog resemble those of humans (Varró et al. 2000; Jost et al. 2005), the reserve to repolarization-delaying drugs may differ substantially between the two species. Consequently, the clinical repolarization-delay potential of drugs with $I_{\mathrm{Kr}} / \mathrm{HERG}$ blocking properties could be underestimated based on experiments in dogs, and using dogs in safety-pharmacology studies to estimate QT-lengthening liability could be misleading. However, there is greater similarity of individual currents in human and dog, and better heart rate correlation between human and dog than human and rabbit (Lengyel et al. 2001) and the similar relative profile of rabbit versus dog $\mathrm{K}^{+}$currents in the Dumaine-Cordeiro study (Dumaine \& Cordeiro, 2007) to the human versus dog results in the present work raise the issue of whether the commonly used, simpler and cheaper rabbit model might be more predictive. QT prolongation by non-cardiovascular drugs is a major problem and considerable resources are expended to optimize QT-liability drug screening in drug development (Vargas, 2008). Our findings have potentially important implications for the optimization of drug screening.

Based on our data, $I_{\mathrm{K} 1}$ block or downregulation/ mutation would not necessarily lead to substantial QT prolongation in humans, unlike in the dog, but a reduction of repolarization reserve would be expected (Roden, 1998; Biliczki et al. 2002; Silva \& Rudy, 2005; Roden, 2006). Therefore, an $I_{\mathrm{K} 1}$ (Kir2.x) channel defect due to ion channel mutations or drug-induced malfunction may not significantly prolong human QT intervals, but could produce excess QT prolongation and life-threatening torsades de pointes in the face of additional repolarization impairment.

The present study is, to our knowledge, the first detailed analysis of the molecular and ionic determinants of repolarization reserve in the human heart, and the first to compare these determinants with those of an animal species commonly used as a model for human cardiac electrophysiology. Our results therefore provide novel fundamental insights into this clinically crucial process.

\section{Potential limitations}

$I_{\mathrm{K} 1}$ flows through a variety of channel subtypes that may be constituted by different alpha-subunits including Kir2.1, Kir2.2, Kir2.3, Kir2.4, TASK and TWIK (Wang et al. 1998; Lopatin \& Nichols, 2001; Melnyk et al. 2002; Dhamoon et al. 2004). The latter two-pore channels do not rectify (Lesage \& Lazdunski, 2000) and were not studied in our experiments, although their contribution to $I_{\mathrm{K} 1}$ cannot be ruled out. Previous reports indicate important species and regional differences in relative expression of Kir2.x proteins (Wang etal. 1998; Melnyk et al. 2002; Dhamoon \& Jalife, 2005). The densities of $I_{\mathrm{K} 1}$ and distribution of Kir2.x proteins differ in atria versus ventricles (Melnyk etal. 2002; Dhamoon \& Jalife, 2005). In the present study, we focused on ventricular tissue exclusively. Kir2.2 has been reported absent in rabbit ventricle but present in human (Wang et al. 1998) and dog (Melnyk et al. 2002) ventricles. Kir2.x proteins not only form homomeric channels, but can also show heteromeric co-assembly (Zobel et al. 2003), complexifying interpretation. Heteromeric assembly of Kir2.1 and Kir2.3 proteins produces $I_{\mathrm{K} 1}$ channels with lower conductance than homomeric Kir2.1 assembly (Yan et al. 2005; Fang et al. 2005). Since the mRNA expression of Kir2.1 and Kir 2.3 in human ventricle was relatively similar, unlike the dog, heteromeric Kir2.1-2.3 channels may be more likely in the human than in the dog ventricle, contributing to the lower $I_{\mathrm{K} 1}$ density that we observed in humans. Indirect evidence indeed points to a significant role for heteromeric Kir2.x channels in human $I_{\mathrm{K} 1}$ (Schram et al. 2003).

All of our human samples were stored in cardioplegic solution following harvesting during transportation to our facility. In preliminary studies in which we stored canine heart samples in cardioplegic solution and then recorded ionic currents and APs, we did not observe any electrophysiological effects of cardioplegic storage. Donors received haemodynamic support with dobutamine prior to heart explantation, a ubiquitous practice in cardiac transplantation. We cannot exclude possible effects of dobutamine infusion on the properties of explanted hearts.

The effects of pharmacological blockade on canine APs vary among different laboratories. For example, the Antzelevitch laboratory has reported larger increases in canine ventricular APD with $\mathrm{K}^{+}$channel blockade (Shimizu \& Antzelevitch, 1999; Tsuboi \& Antzelevitch, 2006) than we observed in the present study. The discrepancies are likely to relate to differences in experimental conditions. For this reason, it is important that comparative studies between species responses are produced within a single laboratory rather than comparing changes observed for one species in one laboratory with those for another species in a different laboratory.

The $\mathrm{Na}^{+}-\mathrm{Ca}^{2+}$ exchanger current (NCX) current was defined and measured as $\mathrm{Ni}^{2+}$-sensitive current. This approach has limitations, because it cannot be excluded that $\mathrm{Ni}^{2+}$ blocks other ionic currents. However, for the measurement of the NCX, we blocked other ionic currents (including $\mathrm{K}^{+}, \mathrm{Na}^{+}$and $\mathrm{Ca}^{2+}$ currents, along with $\mathrm{Na}^{+}-\mathrm{K}^{+}$pump current) according to the experimental approach described by Hobai et al. (1997), which is a relative widely used method for studying NCX current (Tóth et al. 2009).

The $\mathrm{Na}^{+}-\mathrm{K}^{+}$pump is critically dependent on extraand intracellular $\mathrm{Na}^{+}$and $\mathrm{K}^{+}$concentrations, voltage, subcellular space and cAMP levels, and is not well explored 
in dog and human cardiomyocytes (Fuller et al. 2013). Since we have no experimental data regarding this current, we cannot exclude a contribution of species difference in the function of $\mathrm{Na}^{+}-\mathrm{K}^{+}$pump currents to repolarization reserve discrepancies.

Although $I_{\mathrm{Ks}}$ is several-fold larger under square-wave voltage-clamp conditions in dog than man (Fig. 2), there was no significant difference under AP-clamp conditions (Fig. 3). We believe that the apparent discrepancy is due to the fact that during the normal AP, cells spend very little time at potentials for which there is a significant difference in $I_{\mathrm{Ks}}$ (positive to $+20 \mathrm{mV}$; Fig. 2).

The enhanced density of $I_{\mathrm{Ks}}$ in canine versus human heart appears to be due, at least in part, to stronger expression of minK in the dog. However, there is a discrepancy between the Western blot results, showing a $33 \%$ greater expression level in the dog (Table 1), and the immunofluorescence results (Fig. 8), showing an approximately 5 -fold greater expression in canine cardiomyocytes. In addition, if minK overexpression were responsible for greater $I_{\mathrm{Ks}}$ in the dog, kinetics should have differed markedly between the species, which they do not. Therefore, while differences in minK may be involved in the species differences in $I_{\mathrm{Ks}}$, other factors are likely involved and should be addressed in future work.

\section{Conclusions}

Human ventricular cardiomyocytes have reduced repolarization reserve compared to dog. The differential response occurs despite similar $I_{\mathrm{Kr}}$ densities, due to lower $I_{\mathrm{K} 1}$ and $I_{\mathrm{Ks}}$ densities in human hearts. The underlying molecular basis appears to be differential expression of Kir2.x and minK subunits between human and canine hearts. These results suggest that the protection afforded by $I_{\mathrm{K} 1}$ and $I_{\mathrm{Ks}}$ against repolarization stress is limited in humans, making humans susceptible to excess repolarization impairment from $I_{\mathrm{Kr}}$ blocking agents. Animal models are widely used to study cardiac pathophysiology and pharmacological responses. Our findings highlight the importance of caution when extrapolating results from animal models to man, even from species as apparently similar in ionic current mechanisms as dogs.

\section{References}

Abi-Gerges N, Holkham H, Jones EM, Pollard CE, Valentin JP \& Robertson GA (2011). hERG subunit composition determines differential drug sensitivity. Br J Pharmacol 164, 419-432.

Biliczki P, Virág L, Iost N, Papp JGy \& Varró A (2002). Interaction of different potassium channels in cardiac repolarization in dog ventricular preparations: role of the repolarization reserve. Br J Pharmacol 137, 361-368.
Birinyi $\mathrm{P}$, Acsai K, Bányász T, Tóth A, Horváth B, Virág L, Szentandrássy N, Magyar I, Varró A, Fülöp F \& Nánási PP (2005). Effects of SEA0400 and KB-R7943 on $\mathrm{Na}^{+} / \mathrm{Ca}^{2+}$ exchange current and L-type $\mathrm{Ca}^{2+}$ current in canine ventricular cardiomyocytes. Naunyn Schmiedebergs Arch Pharmacol 372, 63-70.

Brendorp B, Elming H, Jun L, Kober L, Malik M, Jensen GB \& Torp-Pedersen C (2001). The DIAMOND Study Group. QTc interval as a guide to select those patients with congestive heart failure and reduced left ventricular systolic function who will benefit from antiarrhythmic treatment with dofetilide. Circulation 103, 1422-1427.

Dhamoon AS \& Jalife J (2005). The inward rectifier current $\left(I_{\mathrm{K} 1}\right)$ controls cardiac excitability and is involved in arrhythmogenesis. Heart Rhythm 2, 316-324.

Dhamoon AS, Pandit SV, Sarmast F, Parisian KR, Guha P, Li Y, Bagwe S, Taffet SM \& Anumonwo JM (2004). Unique Kir2.X properties determine regional and species differences in the cardiac inward rectifier $\mathrm{K}^{+}$current. Circ Res 94, 1332-1339.

Dumaine R \& Cordeiro JM (2007). Comparison of $\mathrm{K}^{+}$currents in cardiac Purkinje cells isolated from rabbit and dog. J Mol Cell Cardiol 42, 378-389.

El-Sherif N (1992). The proarrhythmic mechanism of drugs that prolong repolarisation. Role of early afterdepolarisation. New Trends in Arrhythmias 8, 617-626.

Fang Y, Schram G, Romanenko VG, Shi C, Conti L, Vandenberg CA, Davies PF, Nattel S \& Levitan I (2005). Functional expression of Kir2.x in human aortic endothelial cells: the dominant role of Kir2.2. Am J Physiol Cell Physiol 289, C1134-C1144.

Fuller W, Tulloch LB, Shattock MJ, Calaghan SC, Howie J \& Wypijewski KJ (2013). Regulation of the cardiac sodium pump. Cell Mol Life Sci 70, 1357-1380.

Hobai IA, Khananshvili D \& Levi AJ (1997). The peptide "FRCRCFa", dialysed intracellularly, inhibits the Na/Ca exchange in rabbit ventricular myocytes with high affinity. Pflugers Arch 33, 455-463.

Hohnloser SH \& Woosley R (1994). Sotalol. New Engl J Medicine 331, 31-38.

Hondeghem LM \& Snyders DJ (1990). Class III antiarrhythmic agents have a lot of potential but a long way to go. Reduced effectiveness and dangers of reverse use dependence. Circulation 81, 686-690.

Hund TJ \& Rudy Y (2004). Rate dependence and regulation of action potential and calcium transient in a canine cardiac ventricular cell model. Circulation 110, 3168-3174.

Jost N, Virág L, Bitay M, Takács J, Lengyel C, Biliczki P, Nagy Z, Bogáts G, Lathrop DA, Papp JG \& Varró A (2005).

Restricting excessive cardiac action potential and QT prolongation: a vital role for $I_{\mathrm{Ks}}$ in human ventricular muscle. Circulation 112, 1392-1399.

Larsen AP \& Olesen SP (2010). Differential expression of hERG1 channel isoforms reproduces properties of native $\mathrm{I}(\mathrm{Kr})$ and modulates cardiac action potential characteristics. PLoS One 5, e9021.

Lengyel Cs, Iost N, Virág L, Varró A, Lathrop AD \& Papp JGy (2001). Pharmacological block of the slow component of the outward delayed rectifier current $\left(I_{\mathrm{Ks}}\right)$ fails to lengthen rabbit ventricular muscle $\mathrm{QT}_{\mathrm{C}}$ and action potential duration. Br J Pharmacol 132, 101-110. 
Lesage F \& Lazdunski M (2000). Molecular and functional properties of two-pore-domain potassium channels. Am J Physiol Renal Physiol 279, F793-F801.

Lopatin AN \& Nichols CG (2001). Inward rectifiers in the heart: an update on $I_{\mathrm{K} 1}$ (review). JMol Cell Cardiol 33, 625-638.

Lu HR, Mariën R, Saels A \& De Clerck F (2001). Species plays an important role in drug-induced prolongation of action potential duration and early afterdepolarizations in isolated Purkinje fibers. J Cardiovasc Electrophysiol 12, 93-102.

Lu Z, Kamiya K, Opthof T, Yasui K \& Kodama I (2001). Density and kinetics of $I_{\mathrm{Kr}}$ and $I_{\mathrm{Ks}}$ in guinea pig and rabbit ventricular myocytes explain different efficacy of $I_{\mathrm{Ks}}$ blockade at high heart rate in guinea pig and rabbit: implications for arrhythmogenesis in humans. Circulation 104, 951-956.

Maguy A, Le Bouter S, Comtois P, Chartier D, Villeneuve L, Wakili R, Nishida K \& Nattel S (2009). Ion channel subunit expression changes in cardiac Purkinje fibers: a potential role in conduction abnormalities associated with congestive heart failure. Circ Res 104, 1113-1122.

Melnyk P, Zhang L, Shrier A \& Nattel S (2002). Differential distribution of Kir2.1 and Kir2.3 subunits in canine atrium and ventricle. Am J Physiol Heart Circ Physiol 283, H1123H1133.

Nerbonne M \& Kass RS (2005). Molecular physiology of cardiac repolarization. Physiol Rev 85, 1205-1253.

O'Hara T, Virág L, Varró A \& Rudy Y (2011). Simulation of the undiseased human cardiac ventricular action potential: model formulation and experimental validation. PLoS Comput Biol 7(5), e1002061.

Pfaffl WM (2001). A new mathematical model for relative quantification in real-time RT-PCR. Nucleic Acids Res 29, 2002-2007.

Pourrier M, Schram G \& Nattel S (2003). Properties, Expression and Potential Roles of Cardiac K+ Channel Accessory Subunits: MinK, MiRPs, KChIP, and KChAP. JMembrane Biol 194, 141-152.

Roden DM (1998). Taking the "idio" out of "idiosyncratic": Predicting torsades de pointes. PACE 21, 1029-1034.

Roden DM (2006). Long QT syndrome: reduced repolarization reserve and the genetic link. J Intern Med 259, 59-69.

Sale H, Wang J, O’Hara TJ, Tester DJ, Phartiyal P, He JQ, Rudy Y, Ackerman MJ \& Robertson GA (2008). Physiological properties of hERG $1 \mathrm{a} / 1 \mathrm{~b}$ heteromeric currents and a hERG 1b-specific mutation associated with Long-QT syndrome. Circ Res 103, e81-e95.

Schram G, Pourrier M, Wang Z, White M \& Nattel S (2003). Barium block of Kir2 and human cardiac inward rectifier currents: Evidence for subunit-heteromeric contribution to native currents. Cardiovasc Res, 59, 328-338.

Shimizu W \& Antzelevitch C (1999). Cellular basis for long QT, transmural dispersion of repolarization, and torsade de pointes in the long QT syndrome. J Electrocardiol 32, 177-184.

Silva J \& Rudy Y (2005). Subunit interaction determines $I_{\mathrm{Ks}}$ participation in cardiac repolarization and repolarization reserve. Circulation 112, 1384-1391.
Singh BN \& Vaughan-Williams EM (1970). A third class of anti-arrhythmic action. Effects on atrial and ventricular intracellular potentials, and other pharmacological actions on cardiac muscle, of MJ 1999 and AH 3474. Br J Pharmacol 39, $675-687$.

Surawicz B (1989). Electrophysiologic substrate of Torsade de Pointes: Dispersion of repolarisation or early afterdepolarisation? J Am Coll Cardiol 14, 172-184.

Tóth A, Kiss L, Varró A \& Nánási PP (2009). Potential therapeutic effects of $\mathrm{Na}^{+} / \mathrm{Ca}^{2+}$ exchanger inhibition in cardiac diseases. Current Medicinal Chemistry, 16, 3294-3321.

Tsuboi M \& Antzelevitch C (2006). Cellular basis for electrocardiographic and arrhythmic manifestations of Andersen-Tawil syndrome (LQT7). Heart Rhythm 3, 328-335.

Vargas HM, Bass AS, Breidenbach A, Feldman HS, Gintant GA, Harmer AR, Heath B, Hoffmann P, Lagrutta A, Leishman D, McMahon N, Mittelstadt S, Polonchuk L, Pugsley MK, Salata JJ \& Valentin JP (2008). Scientific review and recommendations on preclinical cardiovascular safety evaluation of biologics. JPharmacol Toxicol Methods 58, $72-76$.

Varró A, Baláti B, Iost N, Takács J, Virág L, Lathrop DA, Lengyel C, Tálosi L \& Papp JGy (2000). The role of the delayed rectifier component $I_{\mathrm{Ks}}$ in dog ventricular muscle and Purkinje fibre repolarization. J Physiol 523, 67-81.

Wang Z, Yue L, White M, Pelletier G \& Nattel S (1998). Differential distribution of inward rectifier potassium channel transcripts in human atrium versus ventricle. Circulation 98, 2422-2428.

Yan DH, Nishimura K, Yoshida K, Nakahira K, Ehara T, Igarashi K \& Ishihara K (2005). Different intracellular polyamine concentrations underlie the difference in the inward rectifier $\mathrm{K}^{+}$currents in atria and ventricles of the guinea-pig heart. J Physiol 563, 713-724.

Zicha S, Moss I, Allen B, Varro A, Papp J, Dumaine R, Antzelevich C \& Nattel S (2003). Molecular basis of species-specific expression of repolarizing $\mathrm{K}^{+}$currents in the heart. Am J Physiol Heart Circ Physiol 285, H1641-H1649.

Zobel C, Cho HC, Nguyen TT, Pekhletski R, Diaz RJ, Wilson GJ \& Backx PH (2003). Molecular dissection of the inward rectifier potassium current $\left(I_{\mathrm{K} 1}\right)$ in rabbit cardiomyocytes: evidence for heteromeric co-assembly of Kir2.1 and Kir2.2. JPhysiol 550, 365-372.

\section{Additional information}

\section{Conflict of interest}

None declared.

\section{Author contributions}

Conception and design of the experiments: N.J., L.V., J.Gy.P., A.V., S.N.; collection, analysis and interpretation of data: N.J., L.V., P.C., B.Ö., V.Sz., Gy.S., M.B., Zs.K., I.K., N.N., T.Sz., J.M., M.K., L.G.P., Cs.L., A.V., S.N.; drafting the article and revising it critically for intellectual content: N.J., L.V., P.C., B.Ö., V.Sz., 
Gy.S., J.M., L.G.P., E.W., U.R., P.P.N., J.Gy.P., A.V., S.N. All authors approved the final version of the manuscript.

\section{Funding}

This work was supported by grants from the Hungarian Scientific Research Fund (CNK-77855, K-82079 and NK-104331), the National Office for Research and Technology-Baross Programmes (REG-DA-09-2-2009-0115-NCXINHIB), the National Development Agency and co-financed by the European Regional Fund (TÁMOP-4.2.2/B-10/1-2010-0012; TÁMOP4.2.2.A-11/1/KONV-2012-0035; TÁMOP-4.2.2A-11/1/KONV-
2012-0073 and TÁMOP-4.2.2.A-11/1/KONV-2012-0060), the Hungarian Academy of Sciences, the Canadian Institutes for Health Care Research (MOP 68929), German Hungarian Research Cooperation DFG Grant (436 UNG 113/176/0-1) HU-RO Cross-Border Cooperation Programmes (HURO/0802/ 011_AF-HURO_CARDIOPOL and HURO/1001/086/2.2.1_ HURO-TWIN,) and the Hungarian Academy of Sciences.

\section{Acknowledgements}

The authors thank France Thériault for secretarial help with the manuscript. 